\title{
Rogério Kuga
}

\section{Avaliação endoscópica e histopatológica do estômago excluso após cirurgia bariátrica}

Dissertação apresentada à Faculdade de Medicina da Universidade de São Paulo para obtenção do título de Mestre em Ciências

Área de concentração: Cirurgia do Aparelho Digestivo Orientadora: Dra. Adriana Vaz Safatle-Ribeiro

São Paulo

2007 
Dados Internacionais de Catalogação na Publicação (CIP)

Preparada pela Biblioteca da

Faculdade de Medicina da Universidade de São Paulo

Creprodução autorizada pelo autor

\section{Kuga, Rogério}

Avaliação endoscópica e histopatológica do estômago excluso após cirurgia bariátrica / Rogério Kuga. -- São Paulo, 2007.

Dissertação(mestrado)--Faculdade de Medicina da Universidade de São Paulo. Departamento de Gastroenterologia.

Área de concentração: Cirurgia do Aparelho Digestivo.

Orientadora: Adriana Vaz Safatle-Ribeiro.

Descritores: 1.Cirurgia bariátrica 2.Gastroplastia 3.Derivação gástrica 4.Anastomose em-Y de Roux 5.Endoscopia 6.Estômago/patologia 


\section{DEDICATÓRIA}

À minha querida Karen, companheira de todos os momentos, pela compreensão, com todo o amor e gratidão, dedico este trabalho.

Ao meu filho Erick, razão de nossas vidas, com eterno amor e carinho. 
À minha mãe Mariko, exemplo de dedicação à família, pelo apoio incondicional em todos os momentos, responsável pela minha educação, com todo o amor e gratidão.

Ao meu pai Katashi, apesar de não estar presente fisicamente, com a certeza de estar seguindo e guiando os meus passos. 


\section{AGRADECIMENTOS}

À DRA. ADRIANA VAZ SAFATLE-RIBEIRO, orientadora, exemplo de dedicação acadêmica e familiar, colega de Serviço, agradeço pelo apoio e tempo dedicado em todo o decorrer desta dissertação.

Ao DR. SHINICHI ISHIOKA, todo o meu reconhecimento pelos ensinamentos na endoscopia, apoio e oportunidades na trajetória acadêmica e carreira profissional.

Ao PROF. DR. PAULO SAKAI, todo o meu agradecimento por tornar viável esta pesquisa, apoiar e estimular a sua realização. Eterna gratidão pela oportunidade na vida acadêmica e profissional.

Ao DR. KIYOSHI IRIYA, exemplo de dedicação e sabedoria, minha gratidão pela análise de todas as lâminas de patologia envolvidas neste estudo.

Ao DR. ROBSON KIYOSHI ISHIDA, pela amizade, auxílio durante os procedimentos e dedicação no recrutamento dos pacientes deste estudo.

Ao PROF. DR. JOAQUIM GAMA-RODRIGUES, exemplo de dedicação e sabedoria, agradeço pela oportunidade e paciência desde o início da Graduação. 
Ao DR. CARLOS KIYOSHI FURUYA JR., pela amizade, grande auxílio e paciência na finalização desta dissertação.

Ao PROF. DR. ULYSSES RIBEIRO JR., pela amizade e importantes sugestões na preparação e finalização desta dissertação.

Ao PROF. DR. JOEL FAINTUCH, pesquisador, grande incentivador do estudo e pesquisa dos pacientes bariátricos, pelo auxílio na publicação deste trabalho.

Aos COLEGAS, ESTAGIÁRIOS e FUNCIONÁRIOS do Serviço de Endoscopia Gastrointestinal do Hospital das Clínicas da Faculdade de Medicina da Universidade de São Paulo, pelo auxílio durante a realização deste estudo e dedicada cooperação no dia-a-dia.

Aos amigos EDSON IDE, ELISA RYOKA BABA, SÉRGIO EIJI MATUGUMA e SÉRGIO SHIGETOSHI UEDA, pela amizade e sociedade, agradeço pela confiança e ensinamentos.

Aos PACIENTES envolvidos neste protocolo de pesquisa que aceitaram participar incondicionalmente deste estudo, aprimorando os conhecimentos científicos da equipe e melhorando o atendimento para os próximos. 


\section{NORMALIZAÇÃO ADOTADA}

Esta dissertação está de acordo com:

Universidade de São Paulo. Faculdade de Medicina. Serviço de Biblioteca e Documentação.

Guia de apresentação de dissertações, teses e monografias. Elaborado por Annaliese Carneiro da Cunha, Maria Júlia de A. L. Freddi, Maria F. Crestana, Marinalva de Souza Aragão, Suely Campos Cardoso, Valéria Vilhena. São Paulo: Serviço de Biblioteca e Documentação, 2005.

Referências: adaptado de International Committee of Medical Journals Editors (Vancouver)

Abreviaturas dos títulos dos periódicos de acordo com o List of Journals Indexed in Index Medicus 


\section{SUMÁRIO}

Lista de abreviaturas e siglas

Lista de símbolos

Lista de tabelas

Lista de figuras

Resumo

Summary

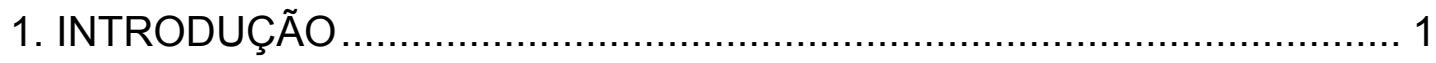

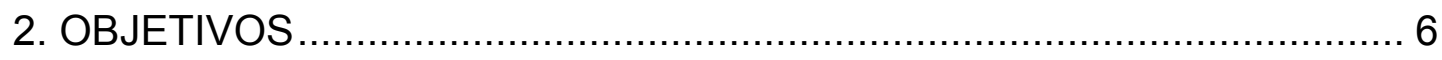

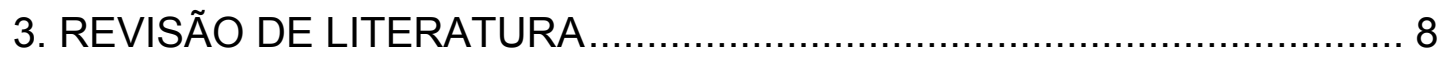

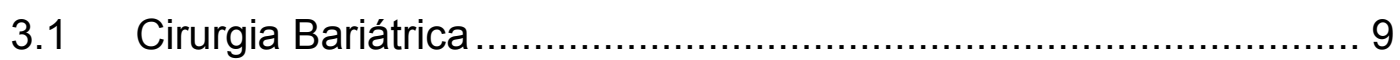

3.2 Endoscopia de duplo balão ............................................ 18

3.3 Avaliação do estômago excluso na cirurgia bariátrica .................. 19

3.4 Helicobacter pylori .......................................................... 22

3.5 Histologia do estômago excluso .......................................... 25

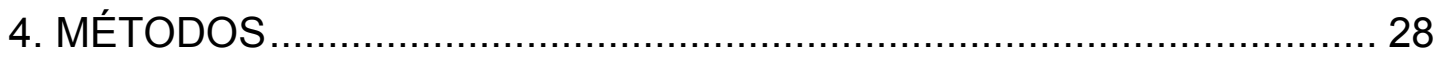

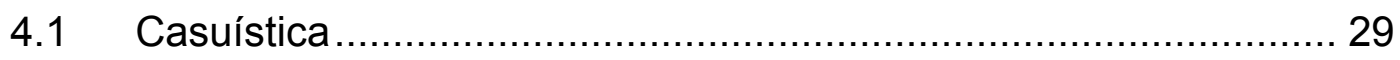

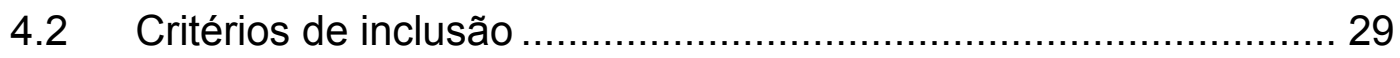

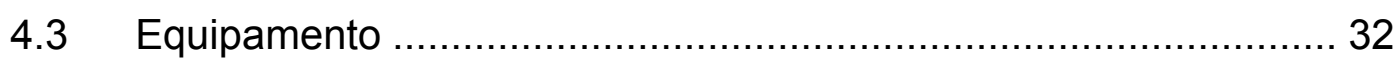

4.4 Técnica de endoscopia de duplo balão ................................... 35

4.5 Análise histológica ......................................................... 39

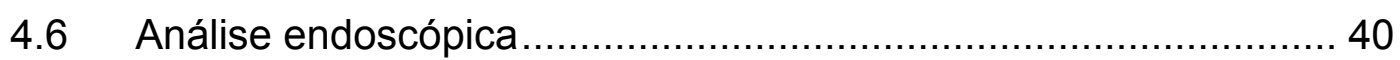

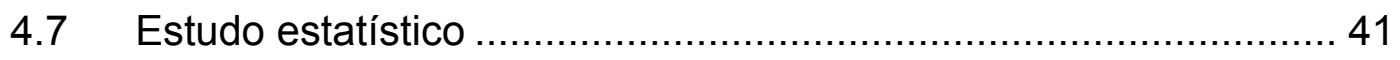

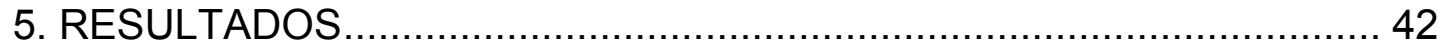

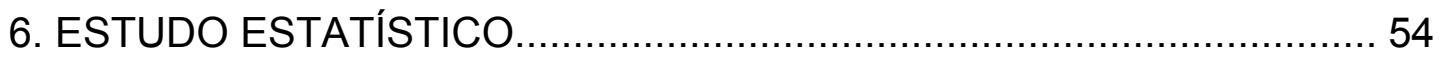

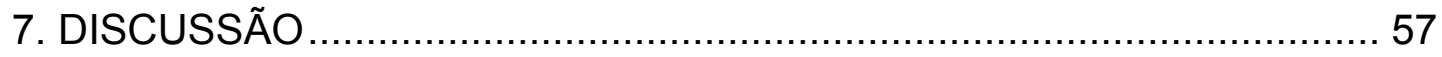

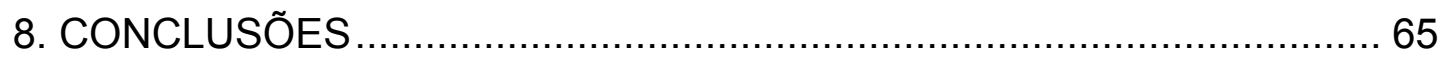

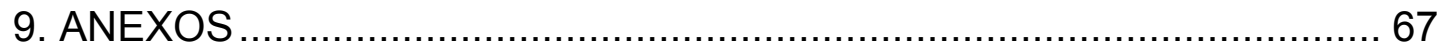

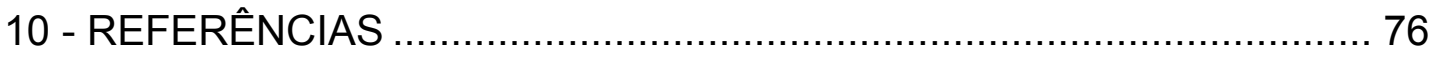


LISTA DE ABREVIATURAS E SIGLAS

\author{
IMC - Índice de Massa Corpórea \\ SUS - Sistema Único de Saúde \\ $\mathrm{OR}$ - odds ratio
}




\title{
LISTA DE SÍMBOLOS
}

\author{
$\mathrm{kg} / \mathrm{m}^{2}$ - quilograma por metro quadrado \\ $\geq$ - maior ou igual \\ cm - centímetro \\ ml - mililitro \\ mm - milímetro \\ $\mu \mathrm{m}$ - micrômetro \\ $\mathrm{kPa}$ - quilopascal
}




\section{LISTA DE TABELAS}

Tabela 1 - Índice de Massa Corpórea (IMC) 3

Tabela 2 - Classificação de Sidney: divisão endoscópica 31

Tabela 3 - Classificação endoscópica de Los Angeles para esofagite erosiva

Tabela 4-Sinais e sintomas dos pacientes submetidos ao procedimento endoscópico de duplo balão

Tabela 5 - Achados endoscópicos: esôfago, coto gástrico proximal, anel e anastomose gastrojejunal

Tabela 6 - Achados endoscópicos: anastomose jejunojejunal e duodeno

Tabela 7 - Achados endoscópicos: estômago excluso .50

Tabela 8 - Histologia do estômago excluso .51

Tabela 9 - Distribuição do Helicobacter pylori no estômago excluso de 35 pacientes submetidos à derivação gástrica em $\mathrm{Y}$ de Roux para obesidade mórbida (Teste Exato de Fischer). 


\section{LISTA DE FIGURAS}

Figura 1 - Gastroplastia vertical com derivação gastrojejunal em Y de Roux

Figura 2 - Derivação jejunoileal de Kremen ...................................... 10

Figura 3 - Derivação jejunocólica de Payne e Lewis ..............................11

Figura 4 - Derivação gástrica de Mason e lto ..................................12

Figura 5 - Derivação gástrica em Y de Roux de Griffen........................12

Figura 6 - Derivação biliopancreática ou cirurgia de Scopinaro ...............13

Figura 7 - Gastroplastia vertical com banda de Mason ......................... 14

Figura 8 - Derivação biliopancreática com duodenal switch ...................15

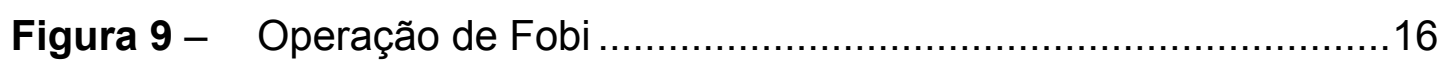

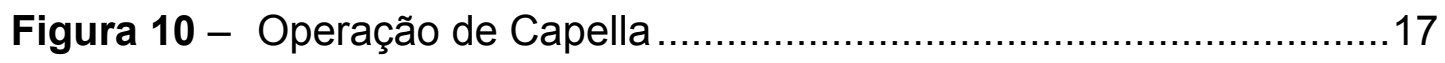

Figura 11 - Trajeto percorrido pelo colonoscópio na avaliação do estômago excluso após a derivação gástrica de Greenville ....20

Figura 12 - A. Enteroscópio de duplo balão com o overtube; B. Overtube; C. Balões adaptados nas extremidades do overtube (seta azul) e do enteroscópio (seta vermelha). 33

Figura 13 - Bomba de ar para insuflação dos balões do overtube e do enteroscópio

Figura 14 - Seqüência esquemática da técnica de introdução do conjunto enteroscópio-overtube 
Figura 15 - Desenho central: Trajeto percorrido pelo enteroscópio de duplo balão até o estômago excluso; A. Coto gástrico proximal; B. Anastomose gastrojejunal; C. Alça jejunal eferente alimentar; D. Anastomose jejunojejunal; E. Alça jejunal biliopancreática; F. Duodeno excluso e papila duodenal maior; G. Piloro sob visão do bulbo duodenal; $H$. Estômago excluso

Figura 16 - Achados endoscópicos do estômago excluso: A. Gastrite enantematosa; B. Gastrite erosiva plana; C. Gastrite erosiva elevada; D. Gastrite hemorrágica; E. Gastrite atrófica; F. Metaplasia intestinal no antro

Figura 17 - Achados histológicos do estômago excluso (H\&E; X20): A. Gastrite crônica; B. Gastrite atrófica; C. Metaplasia intestinal

Figura 18 - Helicobacter pylori pelo método de Giemsa modificado (X100) 52

Figura 19 - Estase biliar no estômago excluso 


\section{RESUMO}

Kuga R. Avaliação endoscópica e histopatológica do estômago excluso após cirurgia bariátrica [dissertação]. São Paulo: Faculdade de Medicina, Universidade de São Paulo; 2007. 86p.

O tratamento cirúrgico para a obesidade mórbida é a única modalidade que consegue a perda de peso sustentada e manutenção a longo prazo. Dentre as técnicas cirúrgicas empregadas, a gastroplastia vertical com derivação gastrojejunal em Y de Roux é uma das mais empregadas mundialmente e em nosso meio. Através desta técnica, o estômago é dividido em duas partes assimétricas, uma vertical e tubular com cerca de $5 \mathrm{~cm}$ de extensão que faz parte do trânsito alimentar e outra denominada exclusa. $O$ seguimento endoscópico pós-operatório de rotina, com o uso do endoscópio convencional, avalia o coto gástrico proximal, mas não alcança o estômago excluso. Com o advento do enteroscópio de duplo balão, tornou-se possível o acesso e avaliação endoscópica, permitindo a realização de biópsias da mucosa do estômago excluso para estudo histológico. Quarenta pacientes submetidos à gastroplastia vertical com derivação gastrojejunal em $\mathrm{Y}$ de Roux foram incluídos no estudo de maneira prospectiva, com período pós-operatório médio de 77,3 meses (36-133), idade média de 44,6 anos $(22-61)$, sendo $85 \%$ do sexo feminino. O sucesso de acesso ao estômago excluso com a utilização do enteroscópio de duplo balão foi de $87,5 \%$ (35 pacientes), com tempo médio decorrido até o estômago excluso de 24,9 minutos $(5-75)$. 0 controle radioscópico concomitante ao exame endoscópico para auxílio direcional foi utilizado em 11 pacientes $(27,5 \%)$. Os achados endoscópicos do estômago excluso nos 35 pacientes foram: normal em 9 pacientes $(25,7 \%)$; gastrite enantemática em 10 (28,6 \%); gastrite erosiva plana ou elevada em $5(14,3 \%)$; gastrite erosiva com sinais de hemorragia em $5(14,3 \%)$ e gastrite atrófica em $6(17,1 \%)$, sendo que dois destes apresentavam concomitantemente áreas sugestivas de metaplasia intestinal no antro que foram confirmadas pelo estudo histológico. Quanto aos achados histológicos, observou-se $100 \%$ de gastrite no estômago excluso, sendo $33 / 35$ pacientes com pangastrite $(94,3 \%)$. A gastrite foi leve em 23/35 $(65,7 \%)$ e moderada em $12 / 35(34,3 \%)$. Gastrite atrófica histológica foi observada em $5 / 35(14,3 \%)$ pacientes e metaplasia intestinal em 4/35 $(11,4 \%)$. Todos os pacientes com metaplasia intestinal possuíam gastrite atrófica. Dos 35 pacientes em que se obteve sucesso de acesso endoscópico do estômago excluso, observou-se positividade para o Helicobacter pylori em $7 / 35$ pacientes $(20 \%)$ e no coto gástrico proximal em $12 / 35$ pacientes $(34,3 \%)$, através da histologia e coloração por Giemsa modificado. Todos os pacientes Helicobacter pylori positivos no estômago excluso, foram positivos no coto gástrico proximal. Não se observou significância estatística na correlação entre os achados endoscópicos e histológicos $(p=0,2)$. Das variáveis estudadas, observou-se que a intensidade da gastrite histológica (inflamação) do estômago excluso e do coto gástrico proximal associou-se à presença de Helicobacter pylori 
$(p<0,05)$, assim como todos os pacientes Helicobacter pylori positivos no estômago excluso também foram positivos no coto gástrico proximal $(p=0,0005)$. Não houve complicações durante e após o procedimento de endoscopia de duplo balão. Em conclusão, o método de endoscopia de duplo balão tem elevada capacidade de alcançar o estômago excluso dos pacientes submetidos à gastroplastia vertical com derivação gastrojejunal em Y de Roux; os achados endoscópicos e histológicos indicam alta prevalência de gastrite crônica, atrofia e metaplasia intestinal no estômago excluso desta população selecionada; o Helicobacter pylori está presente no estômago excluso após derivação gástrica em $Y$ de Roux e todos aqueles Helicobacter pylori positivos no estômago excluso também foram positivos no coto gástrico proximal; e a intensidade da inflamação do estômago excluso e do coto gástrico proximal associou-se à presença de Helicobacter pylori.

Descritores: 1.Cirurgia bariátrica; 2.Gastroplastia; 3.Derivação gástrica; 4.Anastomose em-Y de Roux; 5.Endoscopia; 6.Estômago/patologia 


\section{SUMMARY}

Kuga R. Endoscopic and histopathologic evaluation of the excluded stomach after bariatric surgery [dissertation]. São Paulo: "Faculdade de Medicina, Universidade de São Paulo"; 2007. 86p.

The surgical treatment for morbid obesity is the only modality that in the long term obtains the supported loss of weight and maintenance. Vertical banded Roux-en-Y gastric bypass is the most used technique worldwide and in Brazil. Through this technique, the stomach is divided in two assimetrical pouchs, one vertical and tubular with about $5 \mathrm{~cm}$ of extension and another called excluded. The endoscopic follow-up during the postoperative period using standard gastroscope evaluates the proximal gastric pouch, but doesn't reach the excluded stomach. With the advent of the double balloon enteroscope, it became possible the access and endoscopic evaluation, allowing biopsies of the excluded stomach mucosa for histopathologic study. Forty patients who underwent vertical banded Roux-en- $Y$ gastric bypass were enrolled in this study. The mean postoperative time was 77.3 months (36-133 months). The mean age was 44.6 years old (22-61 years) and $85 \%$ of the patients were female. The success rate of accessing the excluded stomach with the use of double balloon enteroscope was $87.5 \%$ (35 patients), and the mean time to reach the excluded stomach was 24.9 minutes (5-75 minutes). The concomitant radioscopic control was used in 11 patients $(27.5 \%)$. Endoscopic findings of the excluded stomach in the 35 patients were: normal in $25.7 \%$ patients (9); enantematous gastritis were found in 10 patients $(28.6 \%)$; flat or raised erosive gastritis in 5 patients $(14.3 \%)$; hemorrhagic gastritis in 5 patients $(14.3 \%)$ and atrophic gastritis in 6 patientes $(17.1 \%)$. Two patients presented with suggestive areas of intestinal metaplasia in the antrum that had been confirmed by histopathologic study. The histologic findings showed $100 \%$ of gastritis in the excluded stomach; $33 / 35$ patients with pangastritis (94.3\%). Mild gastritis was present in $23 / 35$ patients $(65.7 \%$ ) and moderate gastritis in $12 / 35$ $(34.3 \%)$. Atrophic gastritis were found in $5 / 35$ patients $(14.3 \%)$ and intestinal metaplasia in $4-35(11.4 \%)$. All patients with intestinal metaplasia had atrophic gastritis. Of the 35 patients whom the excluded stomach were reached, Helicobacter pylori was positive in $7 / 35$ patients $(20 \%)$ and in $12 / 35$ patients $(34,3 \%)$ in the proximal pouch through the modified Giemsa staining. Statistical significance was not observed in the correlation between the endoscopic and histologic findings $(p=0,2)$. The intensity of the histologic gastritis (inflammation) of the excluded stomach and the proximal pouch was associated to the presence of Helicobacter pylori $(p<0,05)$. All positive Helicobacter pylori patients in the excluded stomach were also positive in the proximal pouch $(p=0,0005)$. There were no complications during or after the procedure of double balloon endoscopy. In conclusion, the double balloon method has good success rate of access to the excluded stomach after vertical banded Roux-en-Y gastric bypass; the endoscopic and histologic findings indicate high prevalence of chronic gastritis, atrophy and intestinal metaplasia in the excluded stomach in this selected population; the 
Helicobacter pylori is present in the excluded stomach after Roux-en-Y gastric bypass; all patients positive for Helicobacter pylori in the excluded stomach were positive in the proximal pouch; and the intensity of inflammation of the excluded stomach and the proximal pouch associate with the presence of Helicobacter pylori.

Descriptors: 1.Bariatric surgery; 2.Gastroplasty; 3.Gastric bypass; 4.Anastomosis Roux-en-Y; 5.Endoscopy; 6.Stomach/pathology 
1. INTRODUÇÃO 
A obesidade é uma doença crônica que acomete todas as idades, raças, sexos, independente da classe social e que aumenta o risco de desenvolvimento de hipertensão arterial, doença coronariana, doenças cérebro-vasculares, apnéia do sono, diabetes mellitus tipo 2, dislipidemias, lesões articulares e neoplasias ${ }^{1}$. O Índice de Massa Corpórea (IMC) é a razão mais comumente utilizada na mensuração da obesidade ${ }^{2}$. É considerado normal quando o IMC está entre 18 e $24,9 \mathrm{~kg} / \mathrm{m}^{2}$; sobrepeso entre 25 e $29,9 \mathrm{~kg} / \mathrm{m}^{2}$ e obeso quando maior que $30 \mathrm{~kg} / \mathrm{m}^{2}$. A obesidade é considerada mórbida quando o IMC é maior que $40 \mathrm{~kg} / \mathrm{m}^{2}$. Na situação de IMC maior que $50 \mathrm{~kg} / \mathrm{m}^{2}$, é considerada superobesidade (Tabela 1). Existem aproximadamente 350 milhões de obesos e mais de um bilhão de indivíduos com sobrepeso no mundo e sua prevalência vem aumentando. De acordo com o National Center for Health Statistics, cerca de $61 \%$ da população adulta dos Estados Unidos está acima do peso, sendo $30 \%$ obesa e de 5 a $6 \%$ classificada na faixa da obesidade mórbida ${ }^{3}$. No Brasil, o Ministério da Saúde relata que $32,9 \%$ dos brasileiros estão fora da faixa de peso ideal, sendo que $4,8 \%$ dos homens e $11,7 \%$ das mulheres estão na faixa de peso da obesidade mórbida ${ }^{4}$. 
Tabela 1 - Índice de Massa Corpórea $(\mathrm{IMC})^{2}$

\begin{tabular}{lc}
\hline & IMC $\left(\mathbf{k g} / \mathbf{m}^{2}\right)$ \\
\hline Normal & $18-24,9$ \\
Sobrepeso & $25-29,9$ \\
Obesidade & $\geq 30$ \\
Obesidade mórbida & $\geq 40$ \\
Superobesidade & $\geq 50$ \\
\hline
\end{tabular}

A obesidade, particularmente a obesidade mórbida, é uma doença multifatorial, podendo ser desenvolvida pela associação de fatores genéticos, ambientais, sociais, comportamentais, psicológicos, metabólicos e neuroendócrinos ${ }^{5}$. A exata etiologia é desconhecida.

O tratamento da obesidade é realizado através do controle alimentar com dietas balanceadas de baixa caloria, atividade física, terapia comportamental e psicológica, associados ou não a medicamentos anorexígenos e sacietógenos. No entanto, tais métodos muitas vezes são ineficazes na perda de peso, assim como na sua manutenção a longo prazo ${ }^{6}$.

Atualmente, somente a cirurgia bariátrica consegue a perda e manutenção sustentada do peso dos pacientes obesos mórbidos. Desde 1999, o Ministério da Saúde, após consultas à Sociedade Brasileira de Cirurgia Bariátrica, reconheceu a necessidade do tratamento cirúrgico destes pacientes, incluindo a gastroplastia entre os procedimentos ressarcidos pelo Sistema Único de Saúde (SUS). Os critérios para a indicação cirúrgica para o tratamento da obesidade mórbida incluem ${ }^{7,8}$ : 
1 - Pacientes com IMC maior que $40 \mathrm{~kg} / \mathrm{m}^{2}$, com duração maior que dois anos e resistentes aos tratamentos habituais como dietas, exercícios físicos, medicamentos e terapia psicológica;

2 - Pacientes com IMC maior que $35 \mathrm{~kg} / \mathrm{m}^{2}$, portadores de doenças crônicas associadas (diabetes, hipertensão arterial, apnéia do sono, artropatias, hérnia dede disco) agravadas pela obesidade.

Desde a década de 50, passou a ser realizado o tratamento cirúrgico da obesidade, com as diferentes técnicas e aperfeiçoamentos, conseguindose assim, melhores resultados em relação ao tratamento clínico.

São várias as técnicas operatórias descritas e realizadas ao longo do processo de evolução da cirurgia bariátrica, podendo ser divididas de acordo com seus princípios de funcionamento como: restritivas, disabsortivas e mistas.

As operações mistas que possuem componente restritivo e disabsortivo baseiam-se na redução da capacidade gástrica e na derivação gastroentérica. Uma das cirurgias mistas empregadas, a gastroplastia vertical com derivação gastrojejunal em $\mathrm{Y}$ de Roux (Figura 1), consiste na confecção de cavidade gástrica tubular na pequena curvatura envolvida por um anel na sua porção distal a fim de diminuir o tempo de esvaziamento gástrico e aumentar o tempo de saciedade, associado à derivação gastroentérica com reconstrução em $\mathrm{Y}$ de Roux ${ }^{9}$. Desta maneira, o alimento ingerido, após atravessar a neocâmara gástrica, passa pela anastomose gastrojejunal, percorre a alça jejunal eferente alimentar por cerca $75-150 \mathrm{~cm}$, recebe o conteúdo biliopancreático pela anastomose jejunojejunal término-lateral ou látero-lateral por alça jejunal que 
dista 30-50 cm do ângulo de Treitz e atinge a alça jejunal comum. Por esta técnica, a avaliação endoscópica da câmara gástrica exclusa remanescente fica comprometida, pouco se conhecendo da sua evolução e desenvolvimento de lesões a longo prazo.

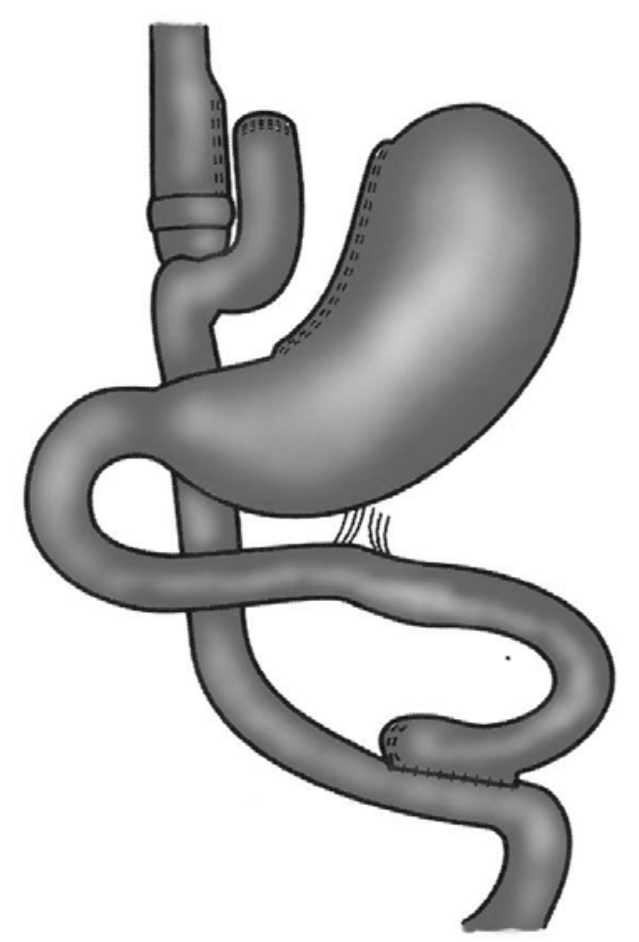

Figura 1 - Gastroplastia vertical com derivação gastrojejunal em Y de Roux

Devido a estas preocupações e com a disponibilidade de um novo tipo de endoscópio denominado enteroscópio de duplo balão ${ }^{10,11}$, desenvolveuse o protocolo do presente estudo onde se propõe analisar a capacidade deste novo equipamento para acessar e realizar a avaliação endoscópica do estômago excluso após a gastroplastia vertical com derivação gastrojejunal em Y de Roux. 
2. OBJETIVOS 
Os objetivos do presente estudo foram:

1. Avaliar a viabilidade do método de endoscopia de duplo balão para acesso ao estômago excluso nos pacientes submetidos à gastroplastia vertical com derivação gastrojejunal em Y de Roux;

2. Analisar os achados endoscópicos e histológicos da mucosa do estômago excluso;

3. Verificar a prevalência de Helicobacter pylori no estômago excluso e no coto gástrico proximal. 
3. REVISÃO DE LITERATURA 


\subsection{Cirurgia Bariátrica}

As primeiras operações bariátricas se baseavam na derivação intestinal, através do desvio do alimento durante o seu trânsito intestinal com conseqüente diminuição da absorção. Esta modalidade de cirurgia disabsortiva, denominada derivação jejunoileal, foi realizada pela primeira vez na Universidade de Minnesota e publicada em 1954 por Kremen ${ }^{12}$ (Figura 2). Tal técnica foi concebida após a observação de pacientes com intestino curto que apesar do aumento da ingestão calórica, não ganhavam peso. O princípio da derivação jejunoileal é a redução da absorção devido à diminuição da exposição da dieta ingerida na superfície mucosa intestinal. O comprimento médio do intestino delgado é de 5 a 6 metros, sendo que a derivação jejunoileal deixa apenas cerca de $40 \mathrm{~cm}$ de intestino delgado exposto aos alimentos ingeridos. $O$ intestino curto criado cirurgicamente resulta num rápido trânsito intestinal do estômago ao cólon, causando freqüentemente diarréia líquida. Cerca de $80 \%$ dos pacientes perdem cerca de um terço do peso inicial. As complicações das derivações jejunoileais são freqüentes e significantes. Diarréia líquida com desidratação e distúrbio hidroeletrolítico, cálculos renais, cirrose hepática e aumento de proliferação bacteriana no 
segmento intestinal derivado, fizeram com que a derivação jejunoileal fosse abandonada, sendo que os portadores deste tipo de operação passaram a ser submetidos a outra técnica de cirurgia bariátrica, preferencialmente a derivação gástrica.

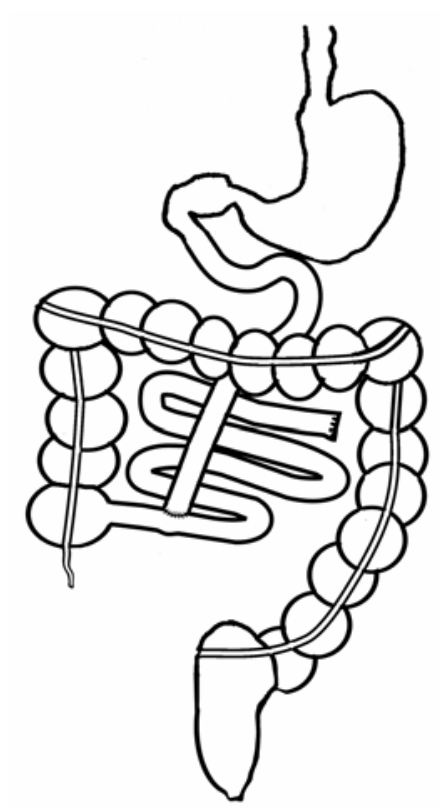

Figura 2 - Derivação jejunoileal de Kremen

Em 1959, Payne propôs a derivação jejunocólica, fazendo a anastomose do jejuno proximal com o cólon transverso ${ }^{13}$. Lewis aumentou o segmento jejunal para $75 \mathrm{~cm}$ do ângulo de Treitz, mantendo a anastomose com o cólon transverso ${ }^{14}$ (Figura 3). Como a válvula ileocecal era excluída do trânsito, também se observava diarréia intolerável, havendo necessidade de nova intervenção cirúrgica em todos os pacientes. 


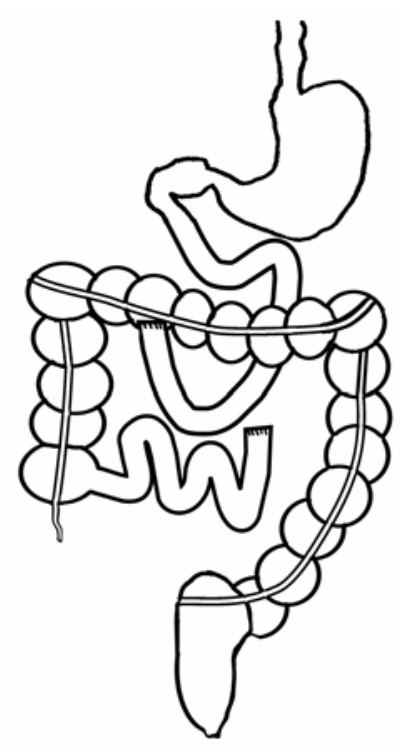

Figura 3 - Derivação jejunocólica de Payne e Lewis

Com a observação de pacientes gastrectomizados que perdiam peso decorrente da diminuição da capacidade da cavidade gástrica e do efeito anorexígeno da cirurgia, Mason e Ito da Universidade de lowa em 1967 propuseram a realização da derivação gástrica ${ }^{15}$, introduzindo o conceito da redução da cavidade gástrica no tratamento da obesidade mórbida e assim substituindo a derivação jejunoileal devido aos seus efeitos colaterais e letais (Figura 4). Esta intervenção cirúrgica consiste na secção horizontal do estômago ao nível do fundo gástrico criando um reservatório de aproximadamente $100 \mathrm{ml}$ e anastomose gastrojejunal de $20 \mathrm{~mm}$ de diâmetro na grande curvatura. Este procedimento demonstrou que era possível o emagrecimento devido à saciedade precoce pela câmara gástrica restrita, porém o refluxo biliopancreático decorrente da anastomose gastrojejunal em alça, incondicionalmente ocasionava gastrite e esofagite importantes. Mason 
e Printen em 1972 modificaram este procedimento, confeccionando a anastomose gastrojejunal mais estreita com cerca de 8 a $12 \mathrm{~mm}^{16}$. Posteriormente, com o intuito de se eliminar o inconveniente do refluxo biliopancreático, Griffen em 1977 foi o primeiro a adotar a reconstrução em Y de Roux nas derivações gástricas ${ }^{17}$ (Figura 5).

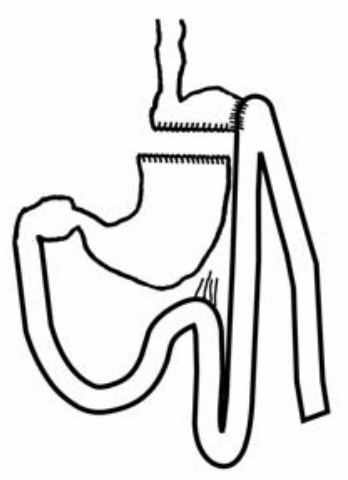

Figura 4 - Derivação gástrica de Mason e Ito

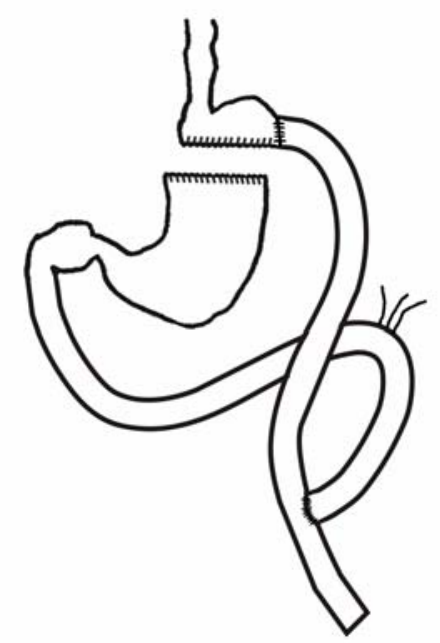

Figura 5 - Derivação gástrica em Y de Roux de Griffen 
Na década de 80 , houve a introdução de outra técnica cirúrgica do tipo disabsortiva, denominada derivação biliopancreática ou cirurgia de Scopinaro $^{18}$ (Figura 6) descrita em 1979, com a intenção de possuir os benefícios da derivação jejunoileal na perda de peso, porém minimizando seus efeitos colaterais. Consiste em: gastrectomia mantendo-se o coto gástrico proximal com cerca de 200 a $400 \mathrm{ml}$, anastomose gastroileal a 250 cm da válvula ileocecal (alça alimentar) e outra anastomose enteral entre a alça biliopancreática e a alimentar a cerca de $50 \mathrm{~cm}$ da válvula ileocecal (alça comum). Este tipo de cirurgia diminui a incidência de enterite decorrente do aumento da proliferação bacteriana na alça jejunal derivada, prevenindo a insuficiência hepática. Possui o inconveniente das fezes volumosas e fétidas, limitando a sua prática.

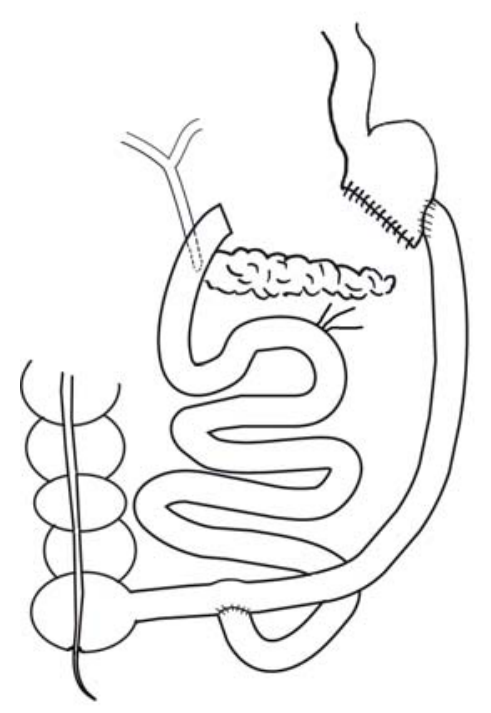

Figura 6 - Derivação biliopancreática ou cirurgia de Scopinaro 
Em 1980, houve a introdução e popularização da gastroplastia vertical com banda de Mason ${ }^{19}$, uma cirurgia puramente restritiva, onde era confeccionada uma bolsa gástrica tubular de pequeno volume na pequena curvatura delimitada na sua extremidade por um anel de polipropileno e lateralmente por uma linha de grampeamento em direção ao ângulo de Hiss (Figura 7). Esta modalidade cirúrgica foi amplamente utilizada na década de 80 pelo baixo índice de complicações intra-operatórias e de desnutrição pós-operatória.

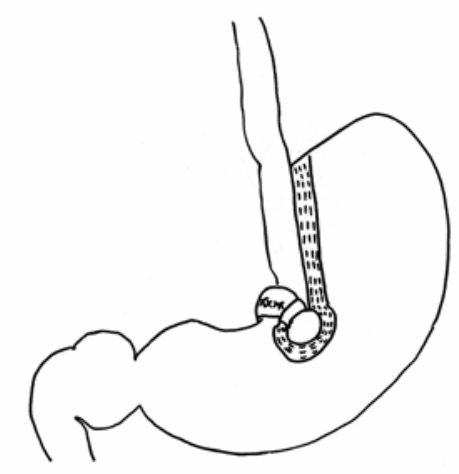

Figura 7 - Gastroplastia vertical com banda de Mason

Na década de 90 , houve o desenvolvimento de uma nova técnica de derivação biliopancreática denominada de duodenal switch ${ }^{20,21}$ (Figura 8), difundida por Marceau. Esta técnica surgiu com o intuito de diminuir os efeitos colaterais da cirurgia de Scopinaro. Realiza-se gastrectomia tubular com preservação do antro e piloro e anastomose duodenoileal. A distância entre a anastomose duodenoileal e a válvula ileocecal é de $250 \mathrm{~cm}$. A anastomose ileoileal se localiza a cerca de 
$100 \mathrm{~cm}$ da válvula ileocecal, criando uma alça comum com cerca de 100 $\mathrm{cm}$. Neste período, observou-se também o retorno das derivações gástricas com algumas modificações.

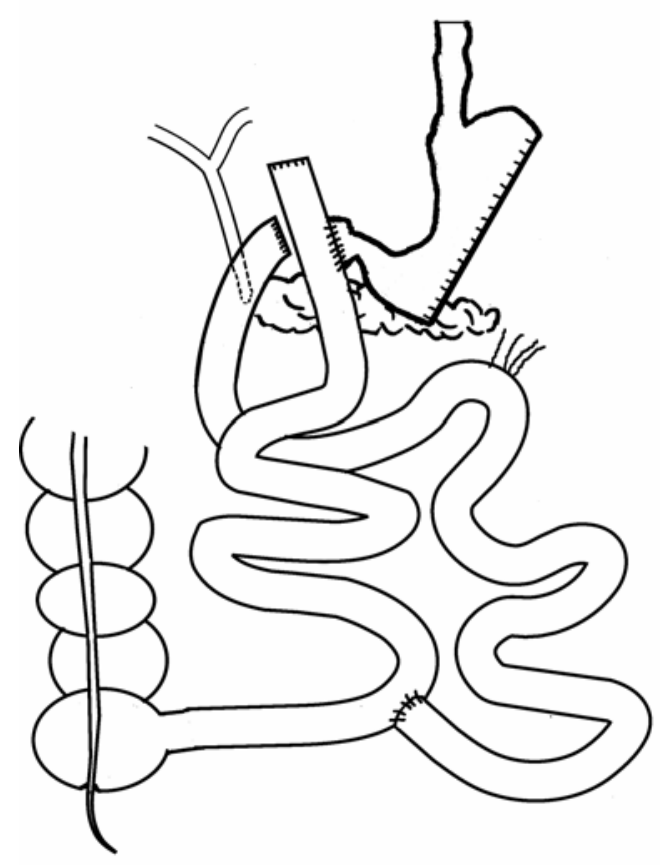

Figura 8 - Derivação biliopancreática com duodenal switch

Fobi, em 1986, realizou a derivação gástrica com colocação do anel de contenção de silicone sem a secção do estômago e posteriormente, em 1991, utilizou a mesma técnica, porém com a secção gástrica vertical, denominando-a de Fobi pouch ${ }^{22-24}$ (Figura 9). A cirurgia de Fobi (Fobi-pouch operation) consiste na transecção vertical do estômago a 6-7 cm da transição esofagogástrica pela pequena curvatura em direção a cárdia e a 
$1 \mathrm{~cm}$ a esquerda da transição esofagogástrica. Na porção distal desta nova câmara gástrica proximal, ajusta-se o anel de silastic de 8 French de diâmetro por 5,5 a $6,5 \mathrm{~cm}$ de comprimento. A anastomose gastrojejunal é término-lateral. A alça jejunal biliopancreática possui cerca de $60 \mathrm{~cm}$ do ângulo de Treitz e a distância entre a anastomose gastrojejunal e a anastomose jejunojejunal possui também cerca de $60 \mathrm{~cm}$. Fobi insere uma gastrostomia de 18 French de diâmetro no estômago excluso e um tubo de silastic radiopaco de $6 \mathrm{~cm}$ em volta da mesma. Tal gastrostomia é mantida aberta por de 36 a 48 horas de pós-operatório e utilizada para medicações ou dieta, se necessárias, sendo removida após 7 a 10 dias de cirurgia.

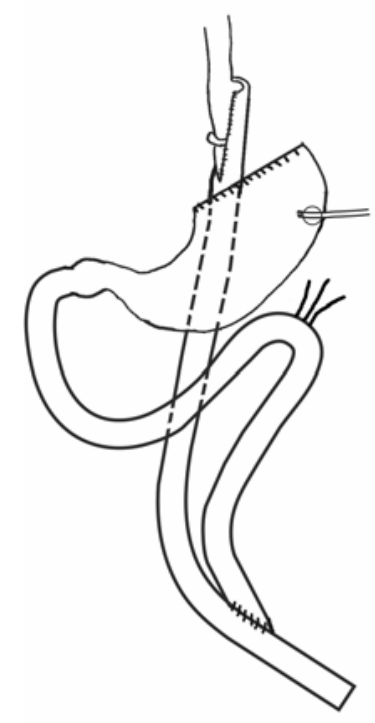

Figura 9 - Operação de Fobi 
Por outro lado, Capella em $1990^{25}$, havia proposto operação semelhante à de Fobi, porém com o reservatório gástrico menor e interpondo a alça jejunal entre a câmara gástrica proximal e o estômago excluso, a fim de diminuir a possibilidade de formação de fístula gastrogástrica (Figura 10).

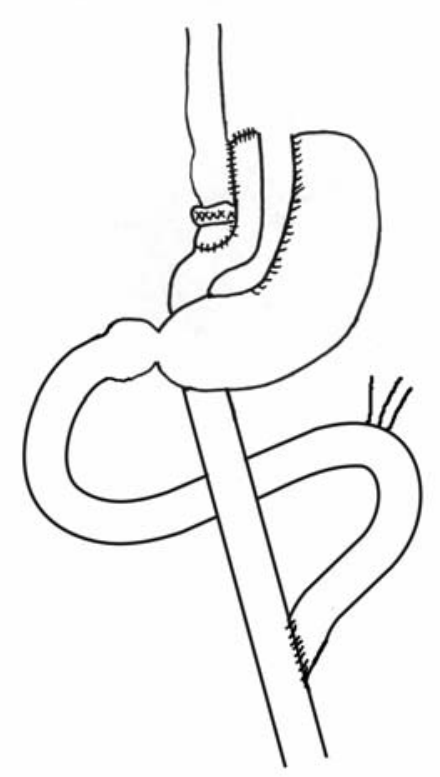

Figura 10 - Operação de Capella

As modificações das derivações gástricas em $\mathrm{Y}$ de Roux propostas por Fobi e Capella são as mais utilizadas no tratamento da obesidade mórbida, sendo consideradas "padrão-ouro" na cirurgia bariátrica.

Em nosso meio, Garrido et al. em $2002^{26}$, utilizando-se de detalhes técnicos de Capella e posteriormente de Fobi, demonstraram grande eficiência na perda duradoura de peso em 4.000 pacientes submetidos à derivação gástrica em $Y$ de Roux com anel de silicone de contenção. 
Com o desenvolvimento das técnicas de laparoscopia, Wittgrove em 1994 foi o primeiro a relatar a realização da derivação gástrica em Y de Roux por via laparoscópica ${ }^{27}$, demonstrando a viabilidade deste tipo de cirurgia pelo acesso laparoscópico.

\subsection{Endoscopia de duplo balão}

A endoscopia do intestino delgado sempre foi um desafio para o gastroenterologista devido ao seu comprimento e mobilidade ao longo do seu trajeto. A tentativa de avaliação endoscópica sempre foi parcial, já que os colonoscópios e enteroscópios utilizados conseguem somente alcançar cerca de 50 a 100 cm após o ângulo de Treitz, pois a formação de alças intestinais durante a introdução do endoscópio limita o seu alcance. Com o desenvolvimento do enteroscópio de duplo balão, pela associação do overtube e do balão acoplado na extremidade do endoscópio que retifica e encurta o trajeto percorrido, consegue-se progredir o intestino delgado mais distalmente.

Yamamoto, em 2001, utilizando um protótipo do sistema de duplo balão, descreveu o método em quatro pacientes, conseguindo alcançar o ceco pela via oral em uma ocasião ${ }^{28}$. Posteriormente, a partir de 2003, observou-se a difusão da técnica e relatos de casuísticas em todo mundo $29-31$. 
Devido à característica deste método, ou seja, conseguir percorrer o intestino delgado em toda sua extensão, surgiu o interesse de se avaliar endoscopicamente órgãos derivados cirurgicamente e não alcançados pelos endoscópios convencionais, como o estômago excluso na operação de Fobi-Capella.

\subsection{Avaliação do estômago excluso na cirurgia bariátrica}

A avaliação e acompanhamento a fim de se entender a natural evolução do estômago excluso nas diferentes técnicas de cirurgia bariátrica sempre foi motivo de preocupação e métodos radiológicos e endoscópicos foram descritos em séries de casos.

Strodel, em $1984,{ }^{32}$ descreveu a utilização do colonoscópio para a avaliação do estômago excluso após a derivação gástrica em Y de Roux em dois pacientes, no entanto, os procedimentos foram realizados no intraoperatório de laparotomia exploradora e com o auxílio do cirurgião na introdução do aparelho, guiando-o através da anastomose jejunojejunal, duodeno até o estômago excluso.

Em 1985, Flickinger ${ }^{33}$ descreveu a utilização do colonoscópio pediátrico em 68 pacientes submetidos à derivação gastrojejunal em $Y$ de Roux na avaliação do estômago excluso, com $68 \%$ de sucesso. No mesmo ano, $\operatorname{Sinar}^{34}$ em uma casuística menor, obteve $65 \%$ de sucesso com a mesma metodologia empregada por Flickinger (Figura 11). Tal sucesso de 
alcance do estômago excluso com o colonoscópio de $160 \mathrm{~cm}$ se deve pelo tipo de derivação gástrica empregada, denominada derivação gástrica de Greenville ${ }^{35}$. Por esta técnica, a distância entre a anastomose gastrojejunal e a jejunojejunal varia de apenas 25 a $40 \mathrm{~cm}$, e a distância entre o ângulo de Treitz e a anastomose jejunojejunal, somente de 10 a $15 \mathrm{~cm}$.

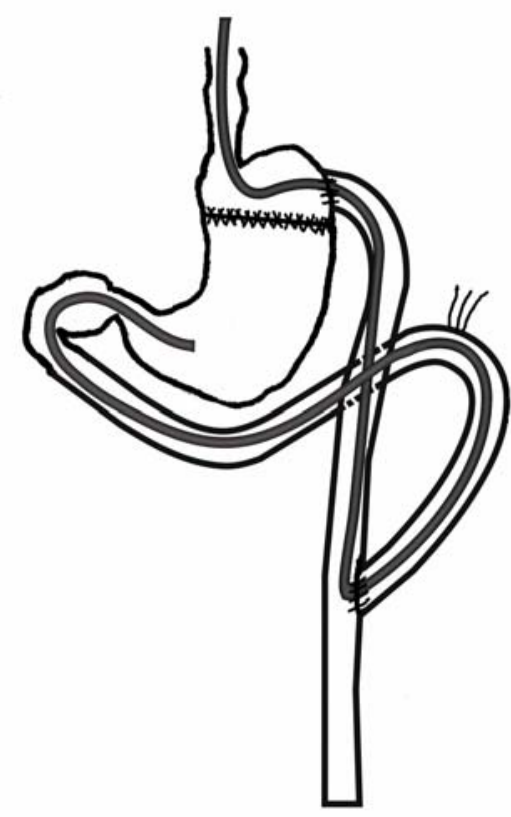

Figura 11 - Trajeto percorrido pelo colonoscópio na avaliação do estômago excluso após a derivação gástrica de Greenville

McNeely, em $1991^{36}$, relatou o acesso do estômago excluso através da via percutânea em um paciente com hemorragia digestiva. A técnica utilizada foi a de punção com agulha na topografia do estômago excluso com auxílio da fluoroscopia. Após a punção, pequenas alíquotas de contraste iodado são injetadas até se observar pregas gástricas à fluroscopia. 
Em seguida, introduz-se o fio guia e um cateter na cavidade gástrica que é insuflada com ar. Com um dispositivo especial de sutura (T-fastners), realizam-se três pontos dispostos de maneira triangular na parede abdominal. Realiza-se incisão de $1 \mathrm{~cm}$ no centro do triângulo, dilata-se 0 trajeto com balão dilatador e introduz-se o broncoscópio.

Fobi, em $1998,{ }^{37}$ descreveu a colocação de marcador radiopaco ao redor da gastrostomia no momento da derivação gástrica. A gastrostomia é removida precocemente, ficando o marcador radiopaco para facilitar a punção do estômago excluso caso haja necessidade de se acessá-lo posteriormente. Se houver, utiliza-se a punção com agulha sob controle fluoroscópico, dilatando-se o trajeto até que seja possível a passagem do endoscópio pediátrico ou broncoscópio.

Sundbom, em $2001,{ }^{38}$ descreveu técnica de acesso do estômago excluso. Previamente ao procedimento, o exato local de punção para acesso do estômago excluso é localizado pela tomografia computadorizada e a punção com agulha é realizada com controle ultra-sonográfico. Após o acesso à cavidade gástrica, é introduzido fio guia e procedida a gastrostomia por punção. Uma semana após esta primeira etapa, dilata-se o trajeto da gastrostomia permitindo a introdução do endoscópio ou broncoscópio.

Em 2002, Silecchia ${ }^{39}$ utilizou a gastroduodenoscopia virtual por tomografia computadorizada em cinco pacientes no pós-operatório de derivação gástrica em $Y$ de Roux. $O$ estômago excluso foi puncionado sob controle tomográfico e nele injetado 300 a $500 \mathrm{ml}$ de ar ou água. Com isso, tornou-se viável a aquisição de imagens por esta técnica. 
Finalmente em 2005, Sakai et al. ${ }^{40}$ descreveram a viabilidade da endoscopia do estômago excluso em cinco de seis pacientes avaliados utilizando-se o enteroscópio de duplo balão, tornando-se factível o interesse no estudo destes pacientes numa maior casuística. Assim, uma vez alcançado o estômago excluso, a possibilidade de se realizar o estudo histológico da câmara gástrica exclusa e de se verificar a presença do Helicobacter pylori pareceu ser de grande valia nestes pacientes. Mais recentemente, Ishida et al. $^{41}$ descreveram a respeito da colonização bacteriana do estômago excluso após a gastroplastia vertical com derivação gastrojejunal em Y de Roux.

\subsection{Helicobacter pylori}

O Helicobacter pylori é uma bactéria pequena, medindo cerca de 2,5 a $4 \mu \mathrm{m}$ de comprimento por cerca de 0,5 a $1 \mu \mathrm{m}$ de largura, espiralada, Gram negativa, produtora de urease e que habita o muco que recobre o epitélio gástrico ${ }^{42}$.

A infecção do estômago humano pelo Helicobacter pylori ocorre mundialmente e é disseminada em muitos países em desenvolvimento, incluindo o Brasil $^{43}$. A maioria dos indivíduos colonizados por esta bactéria não desenvolve manifestações clínicas, porém esta infecção tem sido relacionada com a doença ulcerosa péptica, adenocarcinoma e linfoma gástrico ${ }^{44}$. 
Vários métodos podem ser utilizados na detecção do Helicobacter pylori, podendo ser classificados em métodos invasivos e não-invasivos. Os invasivos envolvem a utilização de biópsia endoscópica. O material endoscópico obtido pode ser cultivado em meios de cultura, colocado em esfregaços, utilizado para pesquisa de urease, para exame histológico ou analisado através de técnicas de biologia molecular através da reação em cadeia da polimerase. Os métodos não invasivos incluem: detecção de anticorpos anti-Helicobacter pylori no soro, suco gástrico, saliva, urina, ou o teste respiratório com uréia marcada $\operatorname{com}^{13} \mathrm{C}$ ou ${ }^{14} \mathrm{C}$. A maioria dos métodos apresenta sensibilidade e especificidade elevadas e a opção por um dos métodos disponíveis depende dos objetivos, da preferência de cada um e da experiência do pesquisador ${ }^{45,46}$.

Dos métodos invasivos de detecção do Helicobacter pylori, o teste da urease e histologia são os mais empregados. O teste da urease pré-formada consiste em introduzir fragmento de mucosa do corpo e antro gástrico em meio contendo uréia como substrato e o vermelho fenol como indicador do $\mathrm{pH}$. O Helicobacter pylori produz urease que promove a degradação da uréia em amônia, elevando o pH e com conseqüente mudança de cor do amarelo para o rosa, indicando a sua positividade ${ }^{47}$. O exame histológico na detecção do Helicobacter pylori apresenta sensibilidade e especificidade elevadas, variando de $95 \%$ a $99 \%{ }^{45,47}$. Por este método, observa-se diretamente a bactéria através da coloração e do preparo adequados. A observação de microorganismos curvos ou espiralados é habitualmente indicativa de infecção pelo Helicobacter pylori. Várias colorações podem ser empregadas para detecção da bactéria. 
Os fragmentos provenientes das biópsias da mucosa gástrica são fixados em formol e incluídos em parafina. Os cortes histológicos podem ser corados pelo Gram, pelo Giemsa modificado ou não, pela prata de acordo com WarthinStarry, pelo método de Gimenez e pela carbolfucsina apresentando-se como boas alternativas para identificação do Helicobacter pylori em cortes histológicos, pois além de sensíveis, são de fácil execução ${ }^{48,49}$.

Desde a sua descoberta em 1983, a associação do Helicobacter pylori com o câncer gástrico tem sido motivo de pesquisa e discussão. Em 1993, um grande estudo (EUROGAST study) envolvendo 17 populações de 13 diferentes países (Estados Unidos, Japão e 11 países da Europa) concluiu que a infecção pelo Helicobacter pylori aumenta em seis vezes o risco de desenvolvimento de câncer gástrico em comparação aos indivíduos sem infecção $^{50}$. Em 1994, apesar de controvérsias, a International Agency for Research on Cancer declarou que o Helicobacter pylori é um carcinógeno do tipo I para adenocarcinoma gástrico ${ }^{51}$. Um estudo de meta-análise demonstrou a relação entre a infecção pelo Helicobacter pylori e o desenvolvimento do câncer gástrico. Neste grande estudo, o odds ratio (OR) foi de 1.92 (95\%; Intervalo de Confiança 1.32 - 2.78), sendo que no grupo de pacientes jovens (<29 anos) o risco de desenvolvimento de câncer gástrico foi maior (OR 9.29) ${ }^{52}$. Entretanto, a grande evidência na literatura é proveniente de estudo prospectivo japonês com 1526 pacientes acompanhados por 7,8 anos onde o câncer gástrico se desenvolveu em 36 de 1246 pacientes Helicobacter pylori positivos (2,9\%) em contraste com nenhum dos 280 indivíduos Helicobacter pylori negativos ${ }^{53}$. 


\subsection{Histologia do estômago excluso}

Park, em 1986, ${ }^{54}$ comparou os achados histológicos do estômago em 91 pacientes, dividindo-os em três grupos, sendo o primeiro grupo com 34 pacientes no pré-operatório de cirurgia bariátrica; o segundo grupo de 33 pacientes com um ano de pós-operatório da derivação gástrica em Y de Roux e o terceiro grupo de 24 pacientes com dois anos de pós-operatório. A coleta do material para estudo histológico nos 57 pacientes no pós-operatório foi realizada por endoscopia e pela técnica retrógrada pela alça jejunal biliopancreática, utilizando-se o colonoscópio pediátrico. Os grupos pósoperatórios demonstraram $40 \%$ de gastrite histológica superficial não erosiva leve ou moderada, sendo mais freqüente no coto gástrico proximal em comparação ao estômago excluso. Observou-se secreção biliar assim como gastrite endoscópica no estômago excluso em quase $100 \%$ dos pacientes no pós-operatório. Porém, o achado endoscópico no estômago excluso de gastrite enantemática e gastrite hemorrágica ou erosiva, não se correlacionaram com os achados histológicos, sendo discrepantes. Entretanto, não se evidenciou metaplasia intestinal, gastrite atrófica ou displasia no coto gástrico proximal ou no estômago excluso em sua casuística.

A presença de refluxo biliar enterogástrico no estômago excluso foi constatada por Sundbom ${ }^{55}$. Vinte e dois pacientes no pós-operatório de derivação gástrica em $Y$ de Roux para obesidade mórbida foram submetidos ao estudo cintilográfico, sendo constatado refluxo duodenogástrico em $36 \%$ dos pacientes. 
Adicionalmente, pacientes submetidos à gastrectomia parcial possuem maior risco de desenvolverem adenocarcinoma gástrico. O câncer gástrico pós-gastrectomia é decorrente das alterações inflamatórias crônicas proporcionadas principalmente pelo refluxo biliar enterogástrico, assim como provavelmente pela presença do Helicobacter pylori. Sabe-se que nesta população, a presença de bile e do Helicobacter pylori são fatores isolados que podem ocasionar aumento da proliferação celular e aumentar o risco de desenvolvimento de neoplasia ${ }^{56-57}$.

À semelhança do gastrectomizado parcial por doença péptica, a presença de refluxo duodenogástrico e a eventual presença do Helicobacter pylori no estômago excluso em paciente submetido à derivação gástrica em Y de Roux para obesidade poderiam contribuir para carcinogênese gástrica. Tal preocupação também se deve aos relatos de desenvolvimento de adenocarcinoma gástrico no estômago excluso em cinco pacientes, em período pós-operatório que variou de 4 a 22 anos.

Raijman e colaboradores em $1991^{58}$ relataram o desenvolvimento de adenocarcinoma no estômago excluso em paciente do sexo feminino com 5 anos de pós-operatório de derivação gástrica, diagnosticada devido à anemia intensa associada à pesquisa de sangue oculto persistentemente positiva durante seis meses.

Lord e colaboradores em $1997^{59}$ descreveram outro caso de adenocarcinoma no estômago excluso após a derivação gástrica em alça, 13 anos após a cirurgia bariátrica em paciente com anemia ferropriva persistente. 
O diagnóstico foi realizado através da endoscopia retrógrada pela alça jejunal aferente durante o intraoperatório, sendo encontrados dois tumores sincrônicos de $6 \mathrm{~cm}$ e $1,5 \mathrm{~cm}$.

Khitin e colaboradores em $2003^{60}$ publicaram um caso de adenocarcinoma no estômago excluso em paciente com 22 anos de pósoperatório pela técnica de derivação gástrica em $Y$ de Roux. Tal paciente apresentava dor abdominal e massa palpável no epigástrio.

A manifestação clínica de dor abdominal e massa abdominal palpável, foi também manifestada por paciente que apresentou adenocarcinoma no estômago excluso com 8 anos de pós-operatório de cirurgia bariátrica através da derivação gástrica em $Y$ de Roux relatada por Escalona et al. ${ }^{61}$.

Mais recentemente em nosso meio, Corsini et al $^{62}$ relataram o desenvolvimento de adenocarcinoma no estômago excluso em paciente com 4 anos de pós-operatório da cirurgia pela técnica de Fobi-Capella.

Mediante tais constatações é que o presente estudo também se propôs a avaliar a histologia do estômago excluso e presença ou ausência do Helicobacter pylori, assim como a pesquisa de lesões pré-neoplásicas. 
4. MÉTODOS 


\subsection{Casuística}

A casuística é constituída de 40 enfermos submetidos ao tratamento cirúrgico de obesidade mórbida através da gastroplastia vertical com derivação gastrojejunal em $\mathrm{Y}$ de Roux com anel de contenção, em acompanhamento ambulatorial na Disciplina de Cirurgia do Aparelho Digestivo do Departamento de Gastroenterologia do Hospital das Clínicas da Faculdade de Medicina da Universidade de São Paulo.

\subsection{Critérios de inclusão}

O recrutamento foi realizado durante o seguimento ambulatorial destes pacientes e os critérios de inclusão foram:

1. Idade entre 18 a 65 anos independentes do sexo;

2. Submetidos à gastroplastia vertical com derivação gastrojejunal em Y de Roux por via aberta;

3. Seguimento pós-operatório maior que 36 meses e

4. Assinatura do consentimento livre e esclarecido. 
Inicialmente, realizou-se a entrevista baseada no questionário do protocolo e exame físico. Analisou-se o prontuário com vista aos critérios de inclusão, comorbidades, achados clínicos e endoscópicos previamente à cirurgia bariátrica. A inclusão dos pacientes no protocolo não levou em consideração os sintomas destes na ocasião. No entanto, foram questionados quanto à presença de disfagia, anorexia, emagrecimento, anemia, dor abdominal, sensação de empachamento pós-prandial, náuseas, vômitos, diarréia, perda de cabelo e pirose.

A análise incluiu a avaliação deste novo endoscópio de duplo balão para este fim, ou seja, a viabilidade e sucesso de acesso à câmara gástrica exclusa por esta técnica, a identificação da técnica cirúrgica empregada com observação das anastomoses gastrojejunal e jejunojejunal, além da introdução retrógrada do endoscópio até o estômago excluso. Neste, foram realizadas quatro biópsias endoscópicas do antro e quatro do corpo, em frascos separados, para análise histopatológica e pesquisa de Helicobacter pylori. Adicionalmente, realizaram-se biópsias do coto gástrico proximal também para estudo histológico e pesquisa de Helicobacter pylori. Pela visão endoscópica, observaram-se a ocorrência de gastrite, úlcera e outras anormalidades sendo a gastrite classificada de acordo com a Classificação de Sidney ${ }^{63,64}$ (Tabela 2). 
Tabela 2 - Classificação de Sidney: divisão endoscópica ${ }^{63,64}$

\begin{tabular}{ll} 
Topografia & Corpo \\
& Antro \\
& Pangastrite (corpo e antro) \\
\hline Termos descritivos & Edema \\
& Enantema \\
& Friabilidade \\
& Exsudato \\
& Erosão plana \\
& Erosão elevada \\
& Nodosidade \\
& Hiperplasia das pregas mucosas \\
Atrofia das pregas mucosas & Visibilidade do padrão vascular \\
Áreas de hemorragia intramural \\
endoscópica
\end{tabular}




\subsection{Equipamento}

Para a realização do procedimento, utilizaram-se os equipamentos que compõem o sistema de duplo balão, a seguir:

1. Endoscópio: visão frontal; modelo Fujinon EN-450P5/20; diâmetro externo de $8,5 \mathrm{~mm}$; comprimento de $200 \mathrm{~cm}$; campo de visão de 120 graus; angulação para cima e para baixo de 180 graus, e direita e esquerda de 160 graus; canal de trabalho de 2,2 mm. (Figura 12A);

2. Overtube: modelo Fujinon TS-12140; diâmetro externo de 12,2 mm; diâmetro interno de 10 mm; diâmetro do balão acoplado de $40 \mathrm{~mm}$; comprimento de $145 \mathrm{~cm}$. (Figura 12B);

3. Balão acoplado na extremidade do endoscópio: modelo BS-1; diâmetro de 30 mm. (Figura 12C); 

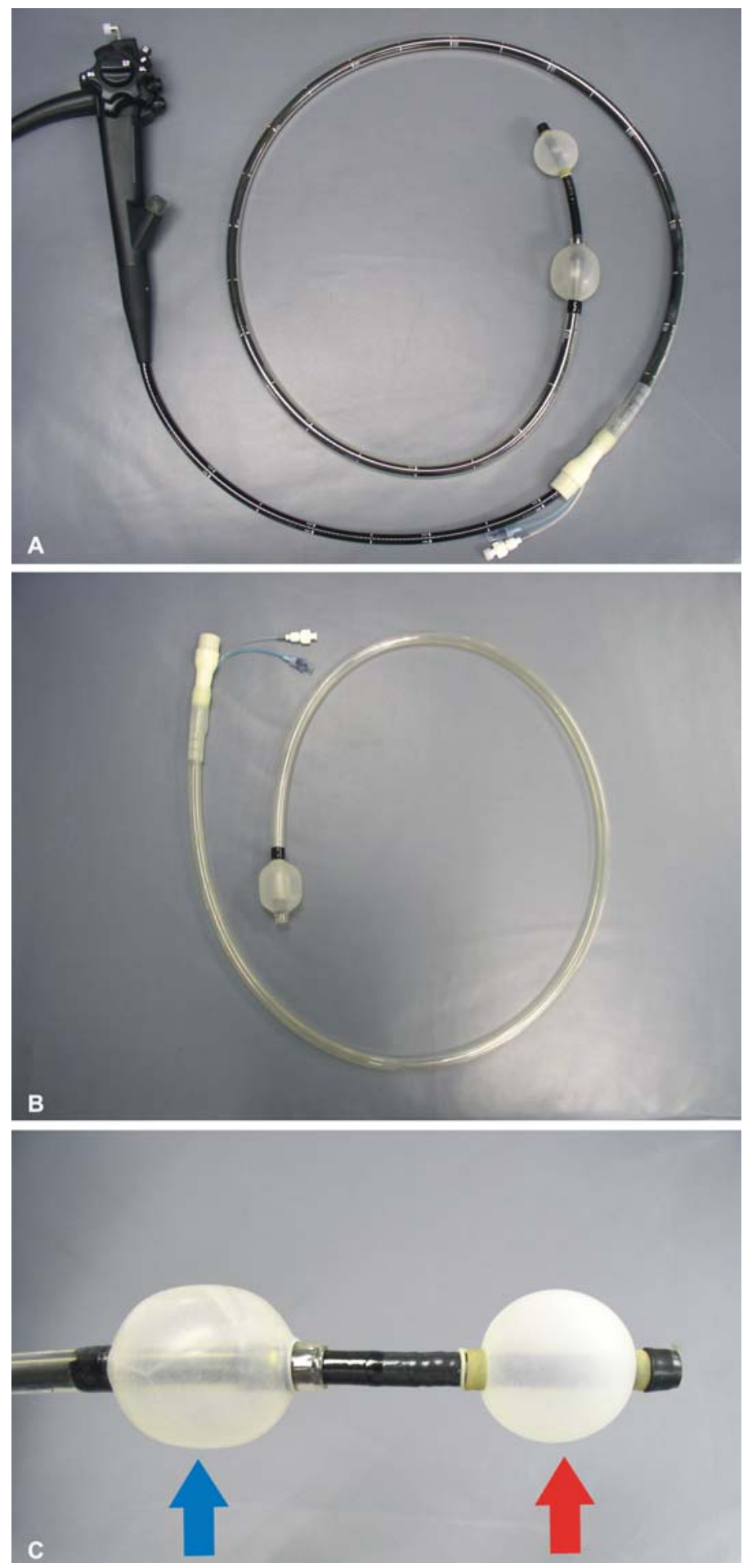

Figura 12 - A. Enteroscópio de duplo balão com o overtube; B. Overtube; C. Balões adaptados nas extremidades do overtube (seta azul) e do enteroscópio (seta vermelha) 
4. Bomba de ar: modelo PB-10; pressão limite de insuflação de 5,6 $\mathrm{kPa} \pm 2 \mathrm{kpa}$ e velocidade de insuflação de $170 \mathrm{ml} \pm 50$ $\mathrm{ml} / 10$ segundos. (Figura 13);

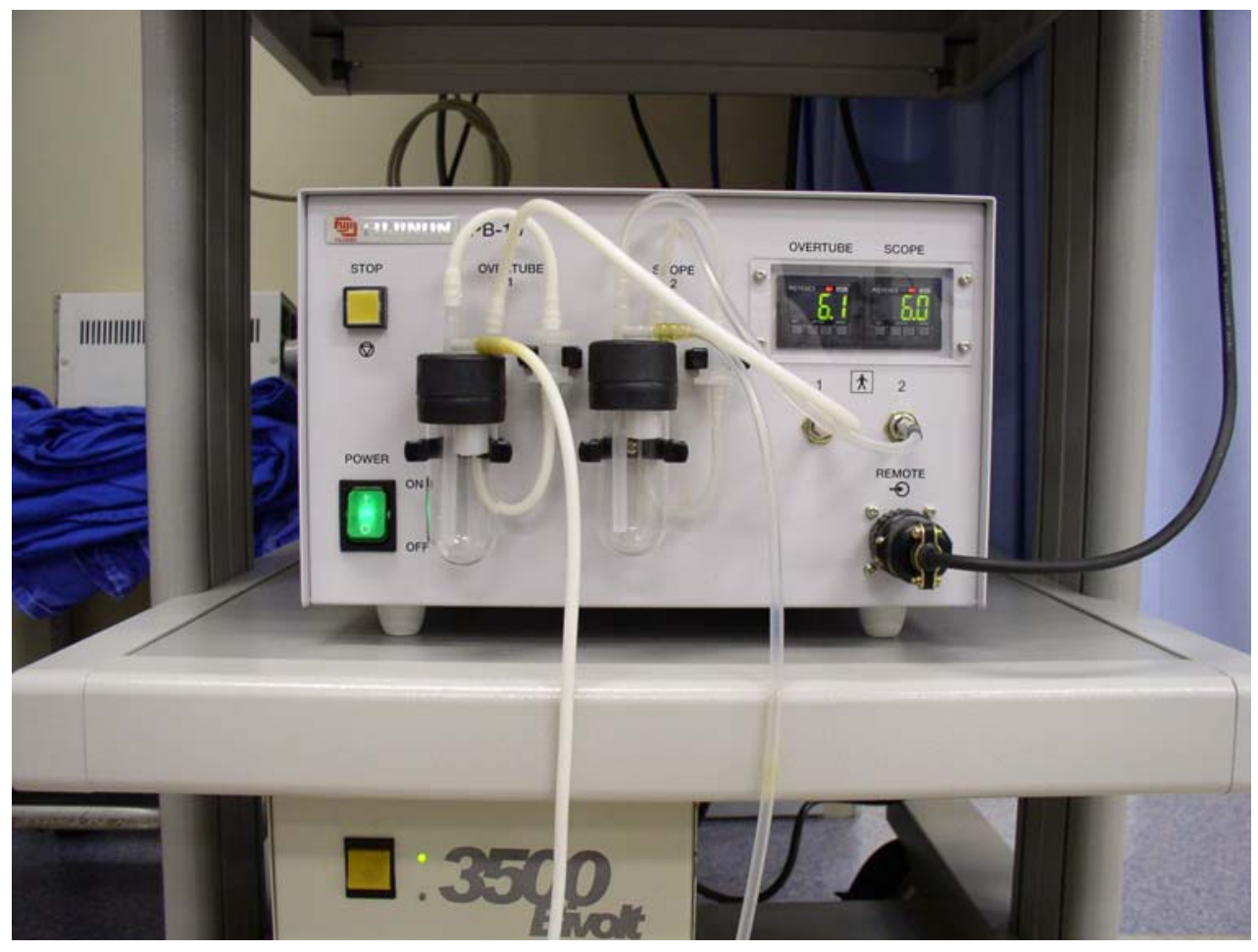

Figura 13 - Bomba de ar para insuflação dos balões do overtube e do enteroscópio

5. Fonte de luz e processadora de imagens: Fujinon série EVE® 400;

6. Monitor: Sony; 14 polegadas; modelo SSM-14N5U e

7. Pinça de biópsia: modelo BF-1824SF, $240 \mathrm{~cm}$ de comprimento. 


\subsection{Técnica de endoscopia de duplo balão}

Antes de se iniciar o procedimento, realizou-se a montagem do sistema que possui a seqüência a seguir: introdução de $10 \mathrm{ml}$ de água filtrada no interior do overtube e passagem do endoscópio por dentro do overtube. Em seguida, acopla-se o balão avulso (BS-1) na extremidade do endoscópio e fixa-se com duas bandas elásticas nas suas extremidades. Adaptam-se as vias de insuflação dos balões na insufladora (PB-10) e testase o funcionamento do sistema.

Todos os procedimentos endoscópicos foram realizados no Serviço de Endoscopia Gastrointestinal do Hospital das Clínicas da Faculdade de Medicina da Universidade de São Paulo pelo próprio autor e auxiliados por um assistente. Para a realização do exame endoscópico, foram necessárias oito horas de jejum oral. Logo após a admissão do paciente no Serviço de Endoscopia, 40 gotas de antifisético (Dimeticona) foram oferecidas por via oral. Posicionou-se o paciente em decúbito lateral esquerdo e realizou-se anestesia tópica da orofaringe com lidocaína a $10 \%$. A sedação consciente consistiu da administração endovenosa de benzodiazepínico (midazolan) associado ao opióde (fentanila), com ou sem o auxílio da fluoroscopia. A depender da disponibilidade, o procedimento foi acompanhado pela anestesiologista, sendo utilizada sedação profunda com propofol se necessário. Antiespamódicos foram administrados à medida da necessidade para facilitar a visualização da mucosa. Utilizou-se oxigênio suplementar por cateter em todos os pacientes durante o exame e a dosagem da medicação 
usada foi individualizada para cada paciente e complementada a critério do médico executante durante o procedimento endoscópico.

A técnica de progressão do conjunto endoscópio-overtube foi realizada à semelhança da descrição de Yamamoto $^{29}$. O procedimento foi realizado pela via oral com lubrificante hidrossolúvel.

A seqüência da técnica de endoscopia com duplo balão é descrita a seguir: com o overtube totalmente recuado, progride-se o endoscópio o mais distante possível, em seguida avança-se o overtube até atingir o seu limite distal, ou seja, quando se encosta ao balão do endoscópio. Neste momento, insuflam-se os dois balões, do overtube e do endoscópio, tracionando-se o conjunto cranialmente. Esta manobra faz o encurtamento do trajeto percorrido até então, permitindo a progressão do endoscópio mais distalmente. Em seguida, desinsufla-se o balão do endoscópio, mantendo-se com o balão do overtube insuflado a víscera já percorrida e encurtada de maneira estável, e progride-se o endoscópio o mais distal possível. Insuflase o balão do endoscópio nesta posição alcançada a fim de se mantê-lo estável neste local. Desinsufla-se o balão do overtube e o progride até alcançar o balão do endoscópio; insufla-se o balão do overtube (o balão do endoscópio já estava insuflado para manter a estabilidade atingida) e, em seguida, traciona-se proximalmente o conjunto endoscópio-overtube para mais um encurtamento do trajeto percorrido (Figura 14). Esta manobra é repetida até se conseguir alcançar o estômago excluso. Os pontos principais e a distância percorrida pelo endoscópio-overtube seriam nesta seqüência: arcada dentária superior até o cricofaríngeo $(15 \mathrm{~cm})$, esôfago $(25 \mathrm{~cm})$, coto 
gástrico proximal $(5 \mathrm{~cm})$ (Figura 15A), região do anel de contenção, anastomose gastrojejunal (Figura 15B), alça jejunal eferente alimentar (100 a $150 \mathrm{~cm}$ ) (Figura 15C), anastomose jejunojejunal (Figura 15D), alça biliopancreática (50 a $75 \mathrm{~cm}$ ) (Figura 15E), ângulo de Treitz, duodeno excluso (20 a 25 cm) (Figura 15F), piloro (Figura 15G) e estômago excluso (15 cm) (Figura 15H). O total percorrido pelo conjunto endoscópio-overtube é de aproximadamente 2 a 3 metros (Figura 15I).

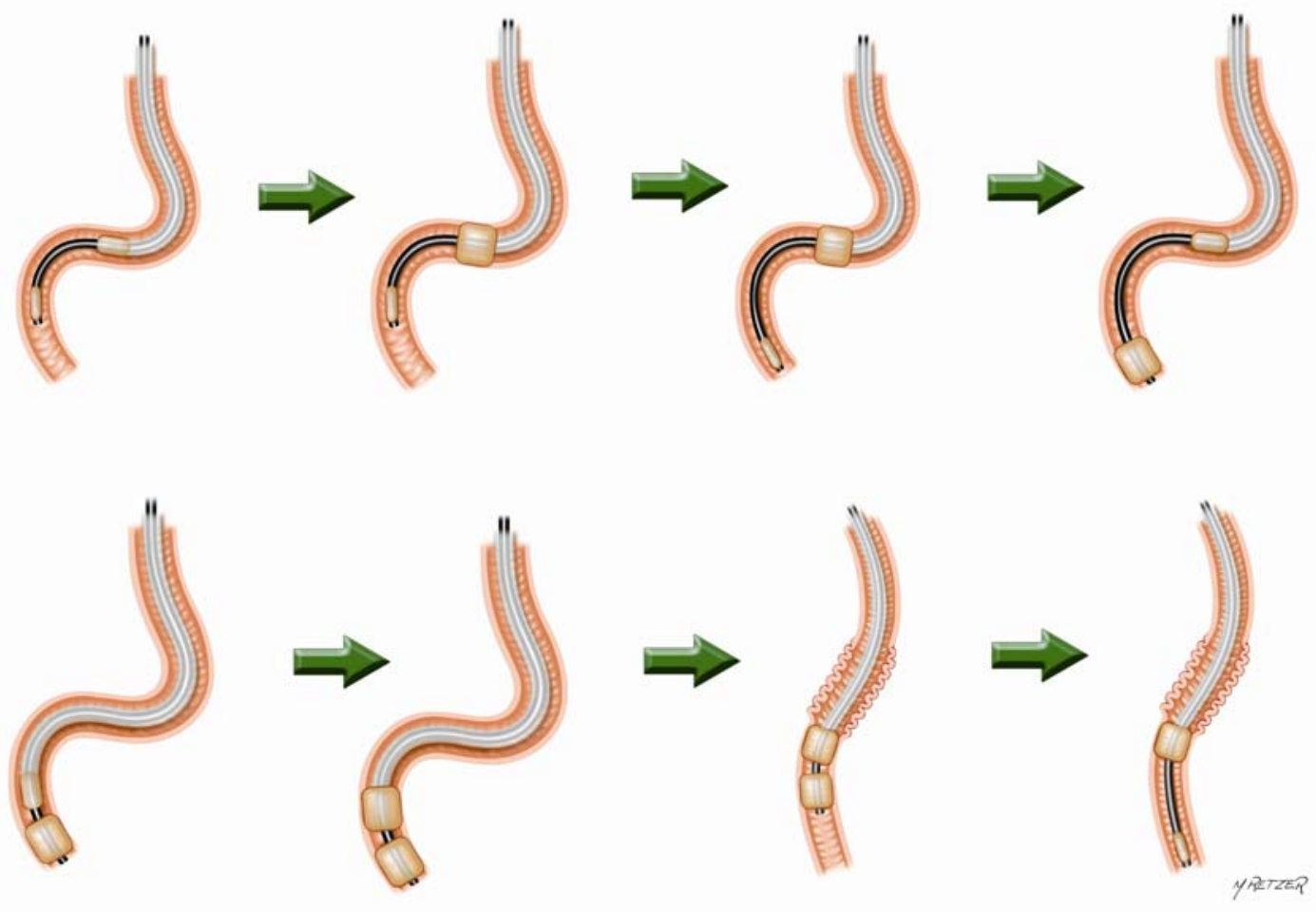

Figura 14 - Seqüência esquemática da técnica de introdução do conjunto enteroscópio-overtube 

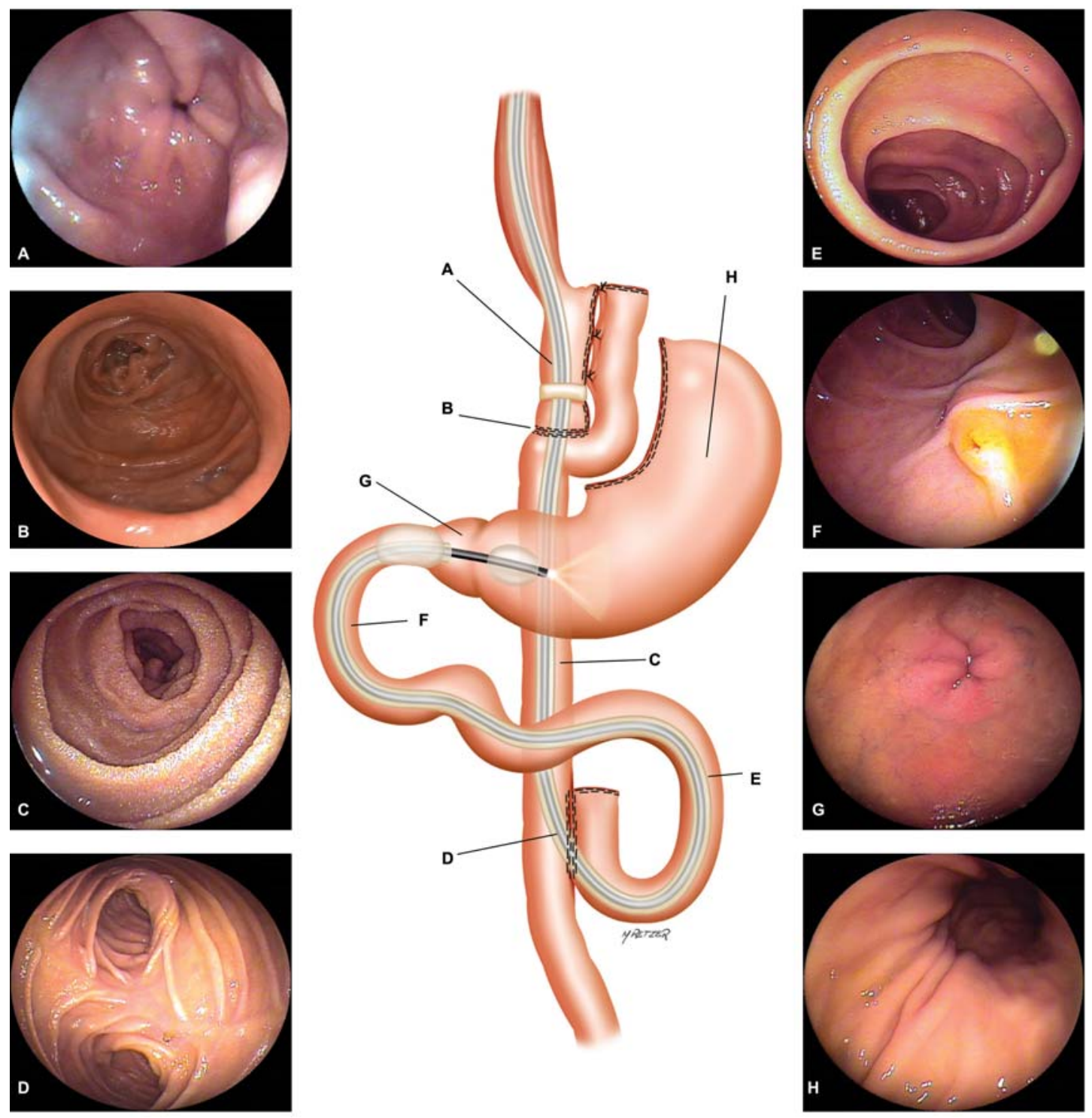

Figura 15 - Desenho central: Trajeto percorrido pelo enteroscópio de duplo balão até o estômago excluso; A. Coto gástrico proximal; B. Anastomose gastrojejunal; C. Alça jejunal eferente alimentar; D. Anastomose jejunojejunal; E. Alça jejunal biliopancreática; F. Duodeno excluso e papila duodenal maior; G. Piloro sob visão do bulbo duodenal; H. Estômago excluso 


\subsection{Análise histológica}

Os fragmentos obtidos através das biópsias gástricas, tanto do coto gástrico proximal (quatro fragmentos) quanto do estômago excluso (corpo = quatro fragmentos, e antro = quatro fragmentos) foram fixados em formalina e embebidos na parafina. Cortes histológicos de $4 \mu \mathrm{m}$ foram corados com hematoxilina-eosina e avaliados quanto à ocorrência de inflamação, atrofia, metaplasia intestinal e displasia. Os graus de inflamação foram classificados como: 0 = nenhum; 1 = leve; 2 = moderado; 3 = intenso de acordo com a Classificação de Sidney ${ }^{65}$. A atrofia foi caracterizada quando houve diminuição leve, moderada ou intensa das glândulas, associada à fibrose de lâmina própria, com ou sem infiltrado inflamatório. A caracterização de metaplasia intestinal foi observada pelo coloração de hematoxilina-eosina, não se utilizando outros métodos de coloração específicos. Utilizou-se a coloração de Giemsa modificado para o diagnóstico de presença ou ausência de Helicobacter pylori. A coloração de Giemsa modificado apresenta as seguintes etapas: xilol, álcoois a 100\% e 95\% e água destilada. Posteriormente, o tecido foi colocado em solução de Jenner, a qual foi diluída 1 grama para $400 \mathrm{ml}$ de metanol, sendo utilizado $85 \mathrm{ml}$ desta solução e misturada com $85 \mathrm{ml}$ de água destilada. O tecido foi imerso na solução de Giemsa acrescida de metanol e glicerol por 45 minutos. Cada lâmina foi rapidamente imersa em água com ácido acético a 1\% (três vezes), em álcool 95\% (três vezes), álcool 100\% (três vezes em dois frascos) e xilol (cinco 
minutos por duas vezes). Como resultado, o núcleo foi corado em azul, o citoplasma em vermelho e as inclusões de organismos em roxo ou azul.

Todos os cortes histológicos foram analisados por um patologista (Dr. Kiyoshi Iriya) e pela orientadora desta dissertação (Dra. Adriana Vaz Safatle-Ribeiro).

\subsection{Análise endoscópica}

Todos os segmentos percorridos foram analisados endoscopicamente e assim divididos: esôfago, coto gástrico proximal, anastomose gastrojejunal, alça jejunal eferente alimentar, anastomose jejunojejunal, alça jejunal biliopancreática, ângulo de Treitz, duodeno e estômago excluso. A presença, ausência ou migração interna do anel de contenção no coto gástrico proximal também foi avaliada.

Os achados endoscópicos do esôfago foram classificados como normal, se não houvesse alterações endoscópicas. Na presença de eritema, friabilidade e edema da mucosa esofágica, os achados foram denominados como "esofagite não erosiva". Na presença de erosões, foram denominadas como esofagite erosiva e classificadas de acordo com a Classificação de Los Angeles $^{66}$ (Tabela 3). Avaliou-se também a presença ou ausência de hérnia hiatal por deslizamento. Os achados da mucosa do coto gástrico proximal foram avaliados de acordo com a Classificação de Sidney ${ }^{63,64}$. A anastomose gastrojejunal foi classificada como: normal ou com a presença 
de erosões ou úlceras. A alça eferente alimentar foi caracterizada como normal ou com lesões à endoscopia. A anastomose jejunojejunal foi classificada como término-terminal, término-lateral, e com ou sem estenose. A alça jejunal biliopancreática foi avaliada como normal ou alterada. No duodeno excluso, observou-se a ocorrência de bulboduodenite, úlceras ou cicatrizes. A gastrite se presente no estômago excluso foi classificada de acordo com a Classificação de Sidney ${ }^{63,64}$.

Tabela 3 - Classificação endoscópica de Los Angeles para esofagite erosiva ${ }^{66}$

\begin{tabular}{cl}
\hline Grau & Descrição endoscópica \\
\hline A & Uma ou mais erosões menores do que $5 \mathrm{~mm}$ \\
\hline B & $\begin{array}{l}\text { Uma ou mais erosões maiores do que } 5 \mathrm{~mm} \text { em sua maior } \\
\text { extensão, não confluentes entre os ápices de duas pregas } \\
\text { esofágicas }\end{array}$ \\
\hline C & $\begin{array}{l}\text { Erosões confluentes (ou contínuas) entre os ápices de pelo } \\
\text { menos duas pregas, envolvendo menos do que } 75 \% \text { do órgão }\end{array}$ \\
\hline D & Erosões ocupando pelo menos $75 \%$ da circunferência do órgão \\
\hline
\end{tabular}

\subsection{Estudo estatístico}

Para a análise estatística, utilizou-se o Teste Exato de Fischer (estudo não-paramétrico), sendo estatisticamente significante quando $p<0,05$. 
5. RESULTADOS 
Quarenta pacientes aceitaram a participação e preencheram os critérios de inclusão do presente estudo. Destes, $85 \%$ eram do sexo feminino e com idade média de 44,6 anos (22 - 61 anos). O período pósoperatório médio foi de 77,3 meses (36 - 134 meses). O controle radioscópico concomitante ao exame endoscópico foi utilizado em 11 pacientes $(27,5 \%)$ no início da casuística. Não houve significância estatística entre o sucesso ou insucesso de se conseguir alcançar o estômago excluso com ou sem o auxílio da radioscopia $(p=0,3)$.

A raça branca predominou com $82,5 \%$ dos pacientes (33), seguida dos pardos $(10 \%)$ e dos negros $(7,5 \%)$.

Os pacientes não foram selecionados baseados na sintomatologia ou história clínica pregressa, no entanto algumas variáveis foram indagadas, tais como a presença de: disfagia, anorexia, emagrecimento, anemia, hemorragia digestiva, dor abdominal, empachamento, náuseas, vômitos, diarréia, perda de cabelo e pirose. Somente 8 de 40 pacientes (20\%) apresentam-se totalmente assintomáticos no momento do exame, negando todos os sinais e sintomas perguntados. Por outro lado, apesar de presente um ou mais sintomas nos outros 32 pacientes (80\%), estes eram de leve intensidade (Tabela 4). 
Tabela 4 - Sinais e sintomas dos pacientes submetidos ao procedimento endoscópico de duplo balão

\section{SINAIS E SINTOMAS}

Anemia

Pirose

Perda de peso

Empachamento

Dor abdominal

Vômitos

Diarréia

Disfagia

Náuseas

Anorexia

Emagrecimento

Hemorragia Digestiva

\section{PRESENTE}

$15(37,5 \%)$

$14(35 \%)$

$13(32,5 \%)$

$10(25 \%)$

$7(17,5 \%)$

$7(17,5 \%)$

$4(10 \%)$

$4(10 \%)$

$2(5 \%)$

$1(2,5 \%)$

$0(0 \%)$

$0(0 \%)$ 
Cada paciente foi submetido somente a uma endoscopia de duplo balão, onde se conseguiu $87,5 \%$ de sucesso de alcance do estômago excluso (35 pacientes). Nos cinco pacientes ( $n^{\text {os. }} 9,12,14,32$ e $38 ; 12,5 \%$ ) nos quais não se conseguiu o objetivo, as falhas foram decorrentes da estenose intransponível da anastomose jejunojejunal (um paciente), a incapacidade de passagem do overtube pelo anel de contenção no estômago do trânsito (um paciente) e alça jejunal biliopancreática longa e com angulações intransponíveis decorrentes de prováveis aderências póscirúrgicas intra-abdominais (três pacientes). Mesmo com radioscopia, em dois destes cinco pacientes não se conseguiu o acesso ao estômago excluso (pacientes 9 e 12). O tempo decorrido médio até o estômago excluso foi de 24,9 minutos (5-75 minutos). O tempo médio total de exame, que compreendeu desde a introdução do endoscópio pela cavidade oral até a sua retirada, incluindo a análise endoscópica e a realização das biópsias do estômago excluso e do coto gástrico proximal foi de 40,7 minutos (20 - 90 minutos).

Os achados endoscópicos relativos ao esôfago, coto gástrico proximal, anel de contenção e anastomose gastrojejunal estão representados na tabela 5 . O esôfago foi considerado normal pela visão endoscópica em 31 pacientes (77,5\%). Diagnosticou-se esofagite não erosiva em 2 pacientes (5\%) e esofagite erosiva em 7 pacientes $(17,5 \%)$, sendo 4 pacientes grau A e 3 pacientes grau B de Los Angeles. Gastrite enantematosa do coto gástrico proximal foi observada em apenas um paciente $(2,5 \%)$. O anel de contenção esteve presente e tópico em 
29 pacientes $(72,5 \%)$; presente e migrado parcialmente para a luz do coto gástrico, visível à endoscopia em 6 pacientes (15\%). O anel estava ausente em 5 pacientes $(12,5 \%)$, todos removidos previamente por migração interna para a luz do coto gástrico, sendo que um por endoscopia e quatro por cirurgia. A anastomose gastrojejunal apresentava erosões na porção jejunal da anastomose em um paciente (2,5\%) e úlcera jejunal em 2 pacientes $(5 \%)$.

Tabela 5 - Achados endoscópicos: esôfago, coto gástrico proximal, anel e anastomose gastrojejunal

\begin{tabular}{lccc}
\hline ESÔFAGO & Normal & $\begin{array}{c}\text { Esofagite não } \\
\text { erosiva }\end{array}$ & $\begin{array}{c}\text { Esofagite } \\
\text { erosiva }\end{array}$ \\
& $77,5 \%(31)$ & $5 \%(2)$ & $17,5 \%(7)$ \\
\hline $\begin{array}{l}\text { COTO GÁSTRICO } \\
\text { PROXIMAL }\end{array}$ & Normal & $\begin{array}{c}\text { Gastrite } \\
\text { enantematosa }\end{array}$ & $\begin{array}{c}\text { Gastrite } \\
\text { erosiva }\end{array}$ \\
& $97,5 \%(39)$ & $2,5 \%(1)$ & 0 \\
\hline $\begin{array}{l}\text { ANEL } \\
\text { Presente e } \\
\text { tópico }\end{array}$ & $\begin{array}{c}\text { Presente e } \\
\text { migrado }\end{array}$ & $\begin{array}{c}\text { Ausente } \\
12,5 \%(5)\end{array}$ \\
\hline $\begin{array}{l}\text { ANASTOMOSE } \\
\text { GASTROJEJUNAL }\end{array}$ & Normal & Erosão jejunal & Úlcera jejunal \\
& $92,5 \%(37)$ & $2,5 \%(1)$ & $5 \%(2)$ \\
\hline
\end{tabular}


As alças jejunais aferente e eferente alimentar após a anastomose gastrojejunal tinham aspecto endoscópico normal em todos os pacientes. A anastomose jejunojejunal era término-lateral em $66,7 \%$ dos pacientes (26/39); látero-lateral em 33,3\% (13/39) e em um paciente não foi possível identificar o tipo de reconstrução devido à estenose, impedindo a sua avaliação. A alça jejunal biliopancreática apresentava-se dentro dos padrões da normalidade nos 35 pacientes em que se avaliou por completo e se conseguiu alcançar o estômago excluso. O duodeno excluso foi considerado normal em $94,3 \%(33 / 35)$ e com erosões em 5,7\% (2/35) (Tabela 6).

Tabela 6 - Achados endoscópicos: anastomose jejunojejunal e duodeno

\begin{tabular}{lccc}
\hline $\begin{array}{l}\text { ANASTOMOSE } \\
\text { JEJUNOJEJUNAL }\end{array}$ & Término-lateral & Látero-lateral & Estenose \\
& $66,7 \%(26 / 39)$ & $33,3 \%(13 / 39)$ & $2,5 \%(1 / 40)$ \\
\hline DUODENO & Normal & $\begin{array}{c}\text { Bulboduodenit } \\
\text { e erosiva }\end{array}$ & \\
& $94,3 \%(33 / 35)$ & $5,7 \%(2 / 35)$ \\
\hline
\end{tabular}

Os achados endoscópicos do estômago excluso nos 35 pacientes, separados topograficamente em corpo e antro, onde se conseguiu o seu alcance, estão representadas na tabela 7. Estômago excluso de aspecto normal em 25,7\% (9/35); gastrite enantematosa em 28,6\% (10/35); gastrite erosiva plana e/ou elevada em 14,3\% (5/35); gastrite hemorrágica, 
caracterizada por erosões puntiformes com hematina aderida e sem hemorragia ativa em 14,3\% (5/35) e gastrite de padrão atrófico, ou seja, com diminuição das pregas gástricas longitudinais de fácil visualização dos vasos submucosos devido ao adelgaçamento da camada mucosa em 17,1\% (6/35) (Figura 16). Destes 6 pacientes, dois ainda apresentavam áreas sugestivas de metaplasia intestinal no antro. 


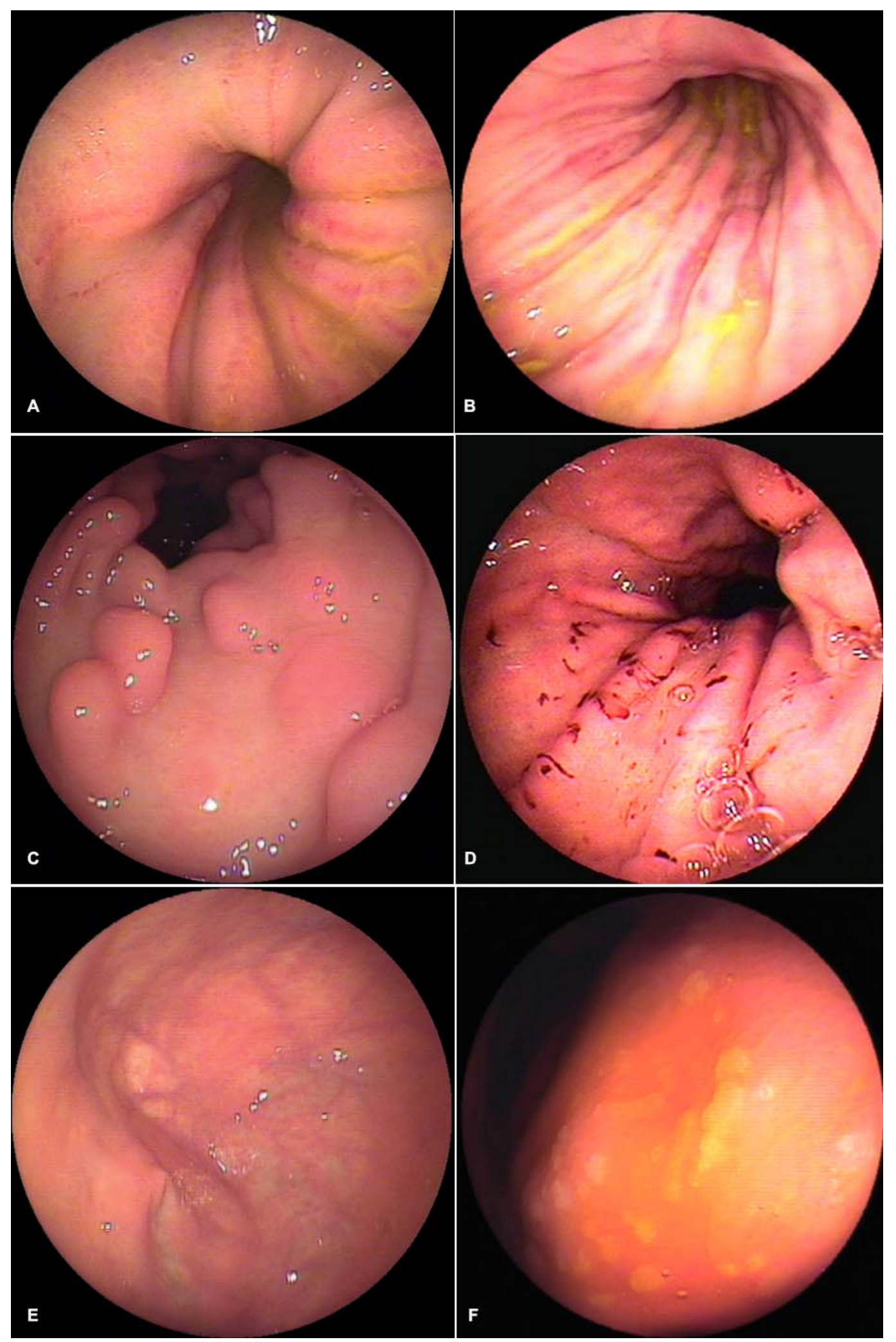

Figura 16 - Achados endoscópicos do estômago excluso: A. Gastrite enantematosa; B. Gastrite erosiva plana; C. Gastrite erosiva elevada; D. Gastrite hemorrágica; E. Gastrite atrófica; F. Metaplasia intestinal no antro 
Tabela 7 - Achados endoscópicos: estômago excluso

\section{ACHADO ENDOSCÓPICO}

Normal

$25,7 \%(09)$

Gastrite enantematosa

$28,6 \%(10)$

Gastrite erosiva plana e elevada

$14,3 \%(05)$

Gastrite hemorrágica

$14,3 \%(05)$

Gastrite atrófica

$17,1 \%(06)^{*}$

* Dois pacientes apresentavam áreas de metaplasia intestinal no antro.

Quanto aos achados histológicos (Tabela 8), observou-se $100 \%$ de gastrite no estômago excluso, sendo $33 / 35$ pacientes com pangastrite (94,3\%). A gastrite foi leve em 23/35 (65,7\%) e moderada em 12/35 (34,3\%). Não se observou gastrite intensa à análise histológica. Gastrite atrófica histológica foi observada em 5/35 (14,3\%) pacientes e metaplasia intestinal em 4/35 (11,4\%) (Figura 17). Todos os pacientes com metaplasia intestinal possuíam gastrite atrófica. Houve correlação entre o achado endoscópico e o histológico quanto à presença de atrofia da mucosa em 50\% (6 achados endoscópicos confirmados histologicamente em 3 pacientes). Em outros dois pacientes onde se confirmou a presença de gastrite atrófica, esta não foi diagnosticada pela endoscopia. A presença de metaplasia intestinal no material proveniente das biópsias do estômago excluso foi confirmada nos 
dois pacientes com achado endoscópico positivo (2/2). No entanto, a metaplasia intestinal foi também diagnosticada em outros três pacientes. Não se observou displasia em nenhum caso.

Tabela 8 - Histologia do estômago excluso

\begin{tabular}{lcc}
\hline ACHADO HISTOLÓGICO & $\begin{array}{c}\text { FUNDOI } \\
\text { CORPO }\end{array}$ & ANTRO \\
\hline Normal & $1(2,9 \%)$ & $1(2,9 \%)$ \\
Gastrite crônica inativa & $25(71,4 \%)$ & $28(80 \%)$ \\
Gastrite crônica ativa & $4(11,4 \%)$ & $4(11,4 \%)$ \\
Gastrite atrófica & $1(2,9 \%)$ & $0(0 \%)$ \\
Gastrite atrófica com metaplasia intestinal & $4(11,4 \%)$ & $2(5,7 \%)$ \\
\hline TOTAL & $35(100 \%)$ & $35(100 \%)$ \\
\hline
\end{tabular}

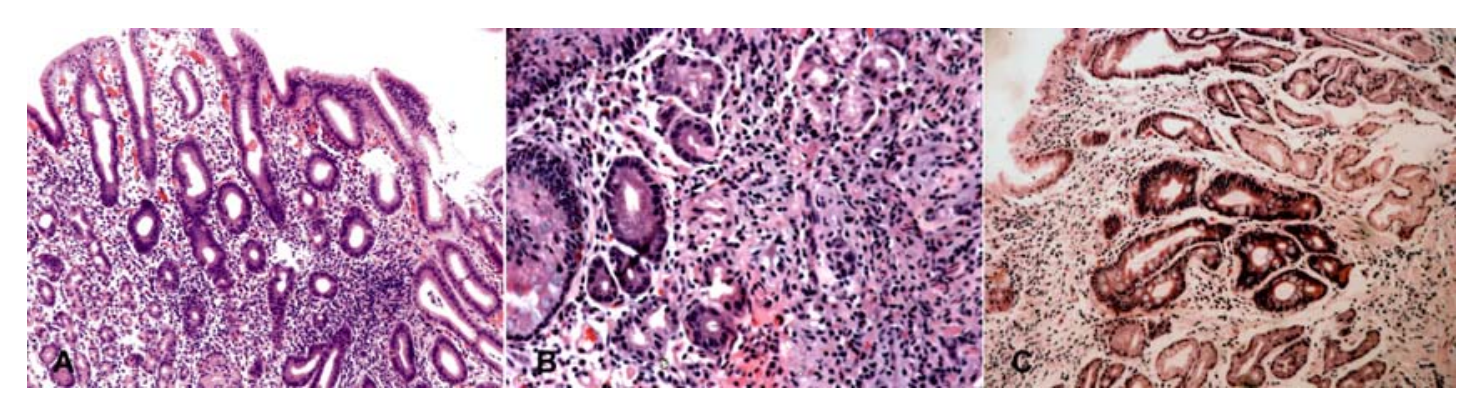

Figura 17 - Achados histológicos do estômago excluso (H\&E; X20): A. Gastrite crônica; B. Gastrite atrófica; C. Metaplasia intestinal 
Através de prontuários, obteve-se a informação de pesquisa de Helicobacter pylori pelo teste da urease em somente nove pacientes no período pré-operatório, sendo que em cinco deles observou-se positividade para a bactéria. Todos pacientes sabidamente positivos para o Helicobacter pylori foram tratados com o intuito de erradicação da mesma no préoperatório. Dos 35 pacientes em que se obteve sucesso de acesso endoscópico do estômago excluso, observou-se positividade para o Helicobacter pylori em $7 / 35$ pacientes (20\%) e no estômago proximal em 12/35 pacientes $(34,3 \%)$, através da histologia e coloração por Giemsa modificado (Figura 18). Todos os pacientes Helicobacter pylori positivos no estômago excluso, foram positivos no coto gástrico proximal.

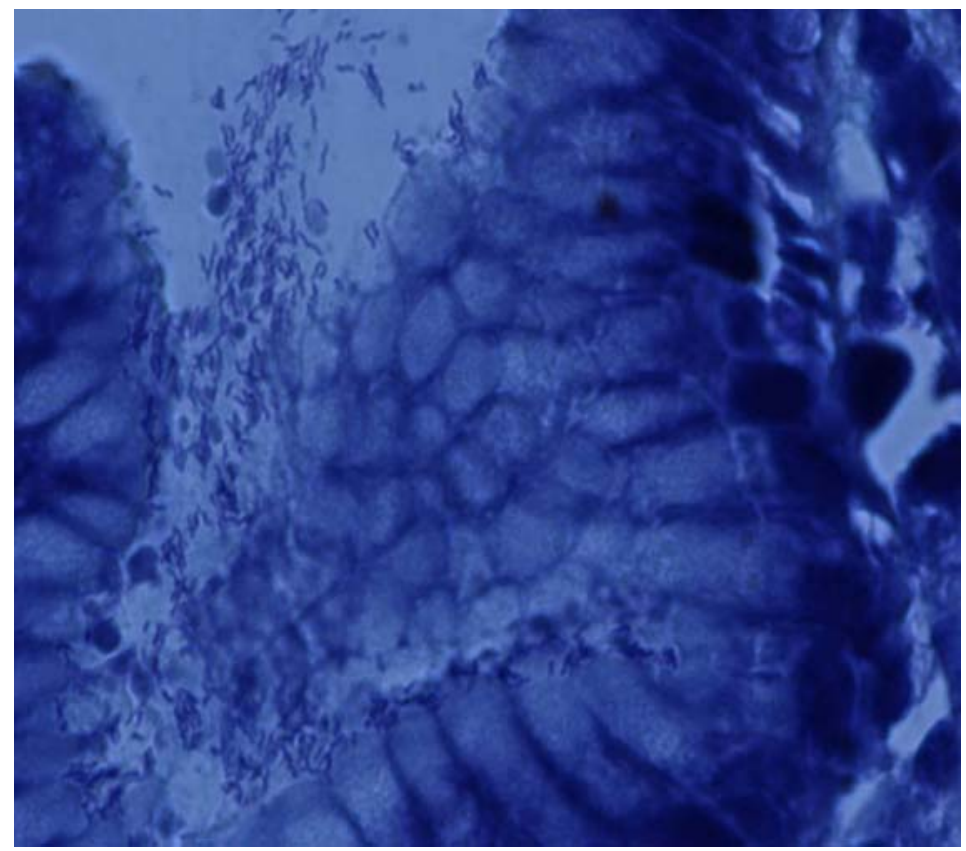

Figura 18 - Helicobacter pylori pelo método de Giemsa modificado (X100) 
Observou-se a presença de lago bilioso no estômago excluso em $68,6 \%$ dos pacientes (24/35), sendo considerado de pequena quantidade em $22,9 \%(8 / 35)$ e de grande quantidade em 45,7\% (16/35) (Figura 19).

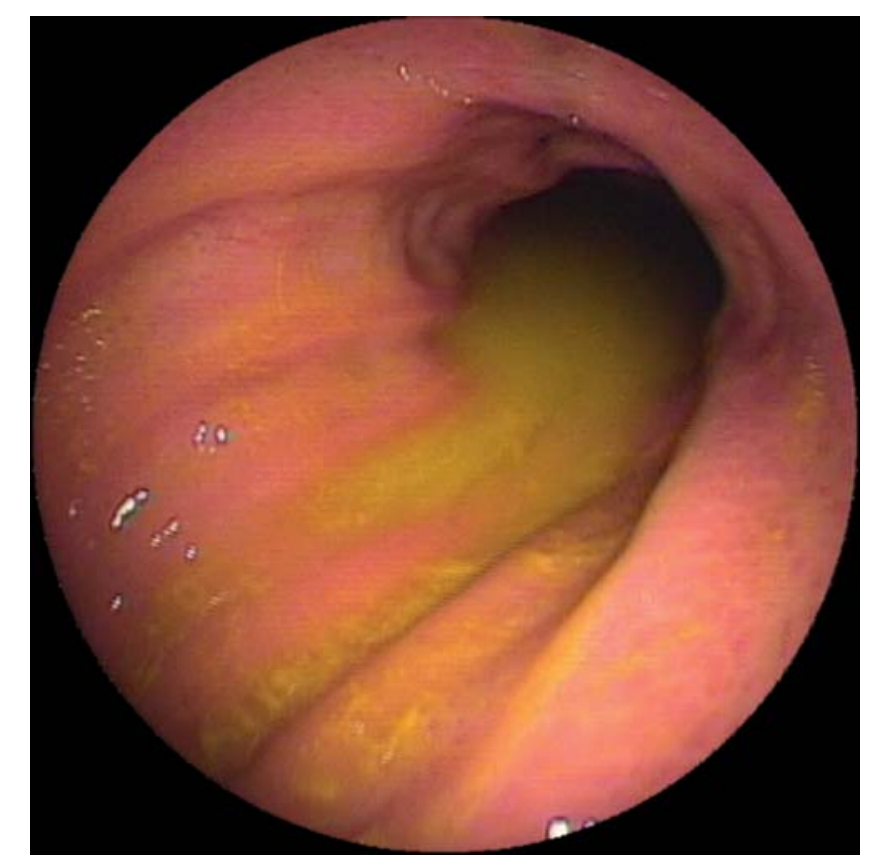

Figura 19 - Estase biliar no estômago excluso

Não houve complicações durante o procedimento tal como depressão cardiorrespiratória e após o exame, tais como dor abdominal, perfuração intestinal, hemorragia ou pancreatite. 
6. ESTUDO ESTATÍSTICO 
Através do Teste Exato de Fischer não se observou significância estatística na correlação entre o uso da radioscopia durante o exame endoscópico e o sucesso de se alcançar o estômago excluso $(p=0,3)$.

Não se demonstrou significância estatística na correlação entre os achados endoscópicos e histológicos $(p=0,2)$ e entre a presença ou ausência de bile e a intensidade da gastrite $(p=0,1)$.

O tempo de pós-operatório também não apresentou correlação estatisticamente significante em relação aos achados endoscópicos $(p=0,1)$ e histológicos $(p=0,08)$.

Em relação à sintomatologia, não se observou correlação estatística entre a presença de anemia ou história de hemorragia digestiva com o achado endoscópico de gastrite hemorrágica $(p=0,2)$. Nos pacientes com queixa de pirose, observou-se uma tendência à existência de esofagite distal não erosiva ou erosiva, porém não estatisticamente significante ( $p=0,07$ ). A presença de dor abdominal leve, não se correlacionou com a intensidade de gastrite endoscópica ou histológica $(p=0,1)$.

Por outro lado, observou-se que a intensidade da gastrite histológica (inflamação) do estômago excluso e do coto gástrico proximal associou-se à presença de Helicobacter pylori ( $p<0,05$ ); e que todos os pacientes 
Helicobacter pylori positivos no estômago excluso também foram positivos no estômago proximal ( $p=0,0005)$ (Tabela 9).

Tabela 9 - Distribuição do Helicobacter pylori no estômago excluso de 35 pacientes submetidos à derivação gástrica em $\mathrm{Y}$ de Roux para obesidade mórbida (Teste Exato de Fischer)

\begin{tabular}{|c|c|c|c|}
\hline & \multicolumn{2}{|c|}{ Helicobacter pylori } & \multirow[t]{2}{*}{$\mathbf{p}$} \\
\hline & Positivo (\%) & Negativo (\%) & \\
\hline \multicolumn{4}{|c|}{$\begin{array}{l}\text { Gastrite - Estômago excluso } \\
\text { (Antro) }\end{array}$} \\
\hline Leve & $2(5,7)$ & $22(62,9)$ & 0,01 \\
\hline Moderada & $5(14,3)$ & $6(17,1)$ & \\
\hline \multicolumn{4}{|c|}{$\begin{array}{l}\text { Gastrite - Estômago excluso } \\
\text { (Corpo) }\end{array}$} \\
\hline Leve & 0 & $23(65,7)$ & 0,003 \\
\hline Moderada & $4(11,4)$ & $8(22,9)$ & \\
\hline \multicolumn{4}{|c|}{$\begin{array}{l}\text { Gastrite - Coto gástrico } \\
\text { proximal }\end{array}$} \\
\hline Leve & $2(5,7)$ & $21(60)$ & 0,02 \\
\hline Moderada & $5(14,3)$ & 7 (20) & \\
\hline \multicolumn{4}{|l|}{ Helicobacter pylori } \\
\hline \multicolumn{4}{|c|}{ Coto gástrico proximal } \\
\hline Positivo & $7(20)$ & $5(14,3)$ & 0,0005 \\
\hline Negativo & 0 & $23(65,7)$ & \\
\hline
\end{tabular}


7. DISCUSSÃO 
A incidência da obesidade é crescente, principalmente no mundo ocidental. O tratamento dos indivíduos em sobrepeso ou obeso pode ser clínico através da abordagem multidisciplinar com a participação de médicos, nutricionistas e psicólogos. Habitualmente são empregados medicamentos que inibem o apetite, drogas que interferem na absorção de gorduras, drogas que aumentam a termogênese e antidepressivos associados à dieta. Por outro lado, para o tratamento eficaz da obesidade mórbida, além da equipe multidisciplinar com apoio dietético e psicológico, somente a modalidade cirúrgica obtém sucesso na perda e manutenção do peso a longo prazo.

Durante a evolução da cirurgia bariátrica, algumas das técnicas empregadas merecem destaque. Uma delas é a gastroplastia vertical por bandagem, técnica de restrição gástrica pura, desenvolvida por Mason ${ }^{19}$. Este tipo de cirurgia dominou o cenário da cirurgia bariátrica durante a década de 1980. No entanto, apesar de sua popularidade, ela passou a ser ineficiente, sendo quase totalmente abandonada, pois além de não perderem peso suficiente durante os primeiros meses de pós-operatório, os pacientes ganhavam peso novamente após 18-36 meses, já que aprendiam a lidar com a restrição imposta pela operação se alimentando de líquidos altamente calóricos. 
Outra técnica é a proposta por Griffen que introduziu o conceito da alça jejunal em $\mathrm{Y}$ de Roux nas cirurgias bariátricas, evitando o refluxo biliopancreático na anastomose gastrojejunal e associando a característica disabsortiva da técnica através da alça em $Y$ de Roux $^{17}$.

A técnica mista, ou seja, a que possui tanto a característica restritiva quanto a disabsortiva, é representada pela gastroplastia vertical com ou sem a colocação do anel de contenção associada à derivação gastrojejunal em $Y$ de Roux, sendo considerada atualmente a técnica cirúrgica de eleição e a mais empregada para o tratamento cirúrgico da obesidade mórbida no Brasil e na América do Norte. Esta técnica associa a capacidade restritiva do coto gástrico proximal tubular com a disabsortiva da alça em $Y$ de Roux. A sua grande adesão é explicada pelos bons resultados obtidos por Garrido et al. ${ }^{26}$ no que diz respeito à perda ponderal duradoura de $35 \%$ a $40 \%$ em relação ao pré-operatório, num período de 12 a 24 meses. Resultados semelhantes também são relatados na literatura mundial por $\mathrm{Fobi}^{67}$ e Capella ${ }^{68}$ que utilizam o anel de contenção e por Wittgrove ${ }^{69}$, que não faz uso do mesmo.

No entanto, apesar de eficiente e praticada aos milhares, esta técnica cirúrgica não permite a avaliação endoscópica de rotina dos órgãos derivados durante os exames com endoscópios convencionais, pouco se conhecendo sobre as suas evoluções naturais.

O presente estudo demonstrou a viabilidade de acesso e alcance do estômago excluso com o uso do enteroscópio de duplo balão elaborado por Yamamoto e inicialmente destinado para a avaliação endoscópica do intestino delgado ${ }^{10,11}$. Até então, durante o seguimento pós-operatório dos 
pacientes submetidos à derivação gastrojejunal em $\mathrm{Y}$ de Roux, os endoscópios convencionais somente avaliavam o que estava ao seu alcance, ou seja, o esôfago, o coto gástrico proximal, a região do anel de contenção, a anastomose gastrojejunal, a alça jejunal aferente e a porção proximal da alça jejunal eferente alimentar. Devido à capacidade controlada da endoscopia de duplo balão, o alcance do estômago excluso é conseguido, onde o trajeto percorrido pelo endoscópio atinge cerca de 2 a 3 metros. O endoscópio possui 2 metros de comprimento, porém seu alcance é maior que o seu comprimento, devido à técnica de duplo balão que encurta o trajeto percorrido através da alternância de insuflação dos balões e tração do conjunto endoscópio-overtube.

No início da casuística, utilizou-se a radioscopia durante o exame endoscópico com o intuito de se compreender a maneira de progressão do enteroscópio de duplo balão, assim como auxiliar as manobras de retificação do conjunto endoscópio-overtube e a mudança de eixo longitudinal durante a sua ascensão pela alça biliopancreática até o duodeno e estômago exclusos. Posteriormente, com o decorrer dos casos, observou-se ser dispensável o uso da radioscopia.

Com o intuito de se entender a evolução das alterações da mucosa do estômago excluso, Gentileschi et al. ${ }^{70}$ compararam os achados histológicos do estômago excluso de 50 suínos submetidos à derivação gastrojejunal em $\mathrm{Y}$ de Roux, no pré-operatório e em 6 meses de pós-operatório, não encontrando anormalidades histológicas. Park et al. ${ }^{54}$ observaram $40 \%$ de gastrite histológica do tipo não erosiva superficial de leve ou moderada intensidade no 
estômago excluso dos pacientes dos grupos de um ou dois anos de pósoperatório. Na presente casuística, $100 \%$ dos pacientes apresentaram gastrite histológica leve ou moderada, sendo $94,3 \%$ de pangastrite.

Fatores que podem corroborar para o achado de gastrite histológica na totalidade dos pacientes é a presença de infecção pelo Helicobacter pylori e o refluxo biliar duodenogástrico ${ }^{71}$.

A infecção crônica pelo Helicobacter pylori parece estar relacionada com o desenvolvimento de gastrite crônica e evolução para condições prémalignas, como a gastrite atrófica e metaplasia intestinal ${ }^{72}$. No presente estudo, o Helicobacter pylori estava positivo em 7/35 pacientes (20\%) do estômago excluso e no coto gástrico proximal em 12/35 pacientes (34,3\%), sendo que todos os pacientes Helicobacter pylori positivos no estômago excluso, foram positivos no estômago proximal. A provável explicação para os cinco pacientes positivos no coto gástrico proximal e negativos no estômago excluso poderia ser por reinfecção no período pós-operatório por outra cepa, onde somente o coto gástrico proximal tornou-se colonizado pela bactéria. Recrudescência da infecção, após insucesso da antibioticoterapia pré-operatória pode ter ocorrido no caso 19 , já que foi positivo tanto no pré como no pós-operatório. A permanência da bactéria no estômago excluso após a derivação gástrica pode exercer papel importante nas alterações histológicas da mucosa a longo prazo.

Existe a preocupação de que a estase gástrica biliar no estômago excluso nos pacientes submetidos à derivação gastrojejunal em $\mathrm{Y}$ de Roux possa funcionar como modelo carcinogênico à semelhança dos pacientes 
submetidos à gastrectomia parcial com reconstrução pela técnica de Billroth II, onde há maior incidência de desenvolvimento de adenocarcinoma de coto gástrico no pós-operatório ${ }^{56,57}$. Park et al. ${ }^{54}$ relataram presença de bile na cavidade gástrica exclusa em praticamente todos dos pacientes submetidos à derivação gastrojejunal. Sundbom et al. ${ }^{55}$ em estudo cintilográfico em tais pacientes constataram a presença de refluxo duodenogástrico em $36 \%$ dos pacientes. Por outro lado, Fujimura et al. ${ }^{73}$ demonstraram a presença de refluxo duodenogástrico fisiológico em $61,9 \%$ dos pacientes saudáveis e assintomáticos com o uso da ultra-sonografia com doppler colorido. Adicionalmente, Fuchs et al. $^{74}$ constataram a presença de refluxo duodenogástrico em $100 \%$ de 20 voluntários assintomáticos durante 24 horas de monitoração através do aspirado gástrico na avaliação do pH e da presença de bilirrubina. Em nossa casuística, observou-se a presença de lago bilioso no estômago excluso em $68,6 \%$ dos pacientes (24/35), sendo considerado de pequena quantidade em 22,9\% (8/35) e em grande quantidade em 45,7\% (16/35). Não houve correlação entre a intensidade da gastrite e a presença de bile na cavidade gástrica, tanto em pequena quanto em grande quantidade $(p=0,1)$. No entanto, todos os pacientes portadores de gastrite atrófica com metaplasia intestinal apresentaram bile em grande quantidade no estômago excluso. Não houve correlação significativa com o tempo de pós-operatório destes pacientes que variou de 50 a 90 meses. Por outro lado, Park et al ${ }^{54}$ não observaram gastrite atrófica tampouco metaplasia intestinal, talvez devido ao fato da casuística se compuser de pacientes em pós-operatório recente de até dois anos. 
A metaplasia intestinal focal no estômago excluso pode ocorrer em até $13 \%$ dos pacientes submetidos à derivação gástrica ${ }^{75}$. Supostamente, esta entidade anatomopatológica pode ser decorrente da inflamação crônica. Tal situação passa a ser preocupante já que Correa $^{76}$ demonstrou que tumores gástricos do tipo intestinal freqüentemente se desenvolvem a partir da seqüência de eventos histológicos: gastrite crônica, metaplasia intestinal, displasia e carcinoma.

Apesar da baixa incidência de neoplasia, a preocupação sobre avaliação da mucosa gástrica exclusa é decorrente da existência de cinco casos de neoplasia na câmara gástrica exclusa desenvolvida de 4 a 22 anos após a cirurgia de derivação gástrica para obesidade mórbida ${ }^{58-62}$.

Com o intuito de se evitar a evolução para displasia e adenocarcinoma, Voellinger et al. $^{77}$ realizaram a ressecção do estômago excluso na mesma ocasião da derivação gástrica em Y de Roux em paciente sabidamente portadora de metaplasia intestinal no antro. Tal ressecção profilática do estômago excluso no mesmo tempo cirúrgico da derivação gástrica é controversa, já que aumenta o tempo pós-operatório e a probabilidade de complicações. No entanto, Csendes et al. ${ }^{78}$ em estudo prospectivo com 400 pacientes, realizaram a gastrectomia do estômago excluso com morbidade de $4,75 \%$ e mortalidade de $0,5 \%$, com o argumento de eliminar os riscos em potencial da manutenção do estômago excluso, como a fístula gastrogástrica, hemorragia, perfuração e o eventual desenvolvimento de câncer. 
A avaliação do estômago excluso não se restringe apenas às condições pré-neoplásicas como a gastrite atrófica e metaplasia intestinal ou ao desenvolvimento de neoplasias malignas, mas também às complicações das doenças ulcerosas pépticas como a hemorragia ou perfuração do duodeno ou estômago excluso. Em estudo retrospectivo de 3.000 derivações gástricas para obesidade mórbida, Printen et al. ${ }^{79}$ observaram oito pacientes com úlcera hemorrágica do estômago e duodeno exclusos $(0,27 \%)$, todos sendo tratados efetivamente através da gastrectomia. Macgregor et al. ${ }^{80}$ relataram em uma série de 4.300 derivações gástricas, 11 úlceras gástricas perfuradas no estômago excluso $(0,26 \%)$. No presente estudo não se encontraram úlceras no estômago excluso.

A viabilidade de acesso do estômago excluso pela técnica de duplo balão não só permite a avaliação endoscópica e a realização de biópsias, mas também a possibilidade de terapêutica endoscópica nestes segmentos exclusos do trato digestório, antes inacessíveis à endoscopia convencional, como as hemostasias e as polipectomias endoscópicas. Outros procedimentos como a gastrostomia endoscópica percutânea e a colangiopancreatografia endoscópica retrógrada são descritas com o uso do endoscópio de duplo balão em tais pacientes submetidos à derivação gástrica em $Y$ de Roux para obesidade mórbida ${ }^{81-83}$.

Em conclusão, o método de endoscopia de duplo balão resolve o problema de se avaliar o estômago excluso após a derivação gastrojejunal em Y de Roux para obesidade mórbida, sendo útil no acesso, vigilância pósoperatória a longo prazo e terapêutica endoscópica. 
8. CONCLUSÕES 
Dentro das condições de realização do presente estudo, pode-se concluir que:

1. O método de endoscopia de duplo balão tem elevado sucesso no acesso ao estômago excluso dos pacientes submetidos à gastroplastia vertical com derivação gastrojejunal em Y de Roux;

2. Achados endoscópicos e histológicos indicam alta prevalência de gastrite crônica, atrofia e metaplasia intestinal no estômago excluso desta população selecionada;

3. Helicobacter pylori está presente no estômago excluso após derivação gástrica em $\mathrm{Y}$ de Roux e todos aqueles Helicobacter pylori positivos no estômago excluso também foram positivos no estômago proximal;

4. Intensidade da inflamação do estômago excluso e do coto gástrico proximal associou-se à presença de Helicobacter pylori. 
Tabela Geral das Observações

\begin{tabular}{|c|c|c|c|}
\hline $\mathbf{N}$ & $\begin{array}{l}\text { Endoscopia pré-operatória } \\
\text { (fundo e corpo) }\end{array}$ & $\begin{array}{l}\text { Endoscopia pré- } \\
\text { operatória (antro) }\end{array}$ & $\begin{array}{l}\text { Helicobacter pylori } \\
\text { pré-operatório }\end{array}$ \\
\hline 1 & Normal & Normal & NC \\
\hline 2 & Normal & Normal & $\mathrm{NC}$ \\
\hline 3 & Normal & Normal & $\mathrm{NC}$ \\
\hline 4 & Normal & Enantematosa & positivo \\
\hline 5 & Normal & Normal & $\mathrm{NC}$ \\
\hline 6 & Normal & Normal & $\mathrm{NC}$ \\
\hline 7 & Normal & Normal & $\mathrm{NC}$ \\
\hline 8 & Normal & Erosiva & NC \\
\hline 9 & NA & NA & NA \\
\hline 10 & Normal & Erosiva & $\mathrm{NC}$ \\
\hline 11 & Normal & Enantematosa & negativo \\
\hline 12 & NA & NA & NA \\
\hline 13 & Normal & Normal & NC \\
\hline 14 & NA & NA & NA \\
\hline 15 & Normal & Normal & $\mathrm{NC}$ \\
\hline 16 & Normal & Erosiva & $\mathrm{NC}$ \\
\hline 17 & Normal & Normal & $\mathrm{NC}$ \\
\hline 18 & Normal & Normal & $\mathrm{NC}$ \\
\hline 19 & Normal & Normal & positivo \\
\hline 20 & Normal & Normal & $\mathrm{NC}$ \\
\hline 21 & Normal & Enantematosa & positivo \\
\hline 22 & Normal & Normal & $\mathrm{NC}$ \\
\hline 23 & Normal & Normal & positivo \\
\hline 24 & Normal & Normal & negativo \\
\hline 25 & Normal & Normal & $\mathrm{NC}$ \\
\hline 26 & Normal & Normal & $\mathrm{NC}$ \\
\hline 27 & Normal & Normal & NC \\
\hline 28 & Enantematosa & Enantematosa & negativo \\
\hline 29 & Erosiva & Erosiva & $\mathrm{NC}$ \\
\hline 30 & Normal & Normal & $\mathrm{NC}$ \\
\hline 31 & Normal & Normal & $\mathrm{NC}$ \\
\hline 32 & NA & NA & NA \\
\hline 33 & Normal & Enantematosa & $\mathrm{NC}$ \\
\hline 34 & Normal & Normal & $\mathrm{NC}$ \\
\hline 35 & Normal & Normal & $\mathrm{NC}$ \\
\hline 36 & Normal & Normal & positivo \\
\hline 37 & Normal & Normal & $\mathrm{NC}$ \\
\hline 38 & NA & NA & NA \\
\hline 39 & Normal & Enantematosa & negativo \\
\hline 40 & Normal & Normal & $\mathrm{NC}$ \\
\hline
\end{tabular}

NA - Não avaliada

NC - Não coletado material para análise 
Tabela Geral das Observações

\begin{tabular}{|c|c|c|c|c|c|c|c|c|c|}
\hline $\mathbf{N}$ & Sexo & Idade & PO & Raça & $\begin{array}{c}\text { Altura } \\
(\mathrm{m})\end{array}$ & $\begin{array}{l}\text { PPO } \\
\text { (kg) }\end{array}$ & $\begin{array}{l}\text { IMC PO } \\
\left(\mathrm{kg} / \mathrm{m}^{2}\right)\end{array}$ & $\begin{array}{c}\text { Peso } \\
\text { atual }(\mathrm{kg})\end{array}$ & $\begin{array}{c}\text { IMC atual } \\
\left(\mathrm{kg} / \mathrm{m}^{2}\right)\end{array}$ \\
\hline 1 & $M$ & 51 & 54 & B & 1,60 & 135 & 52,73 & 81 & 31,60 \\
\hline 2 & $F$ & 50 & 45 & $B$ & 1,53 & 105 & 44,87 & 70 & 29,91 \\
\hline 3 & $\mathrm{~F}$ & 49 & 50 & $B$ & 1,71 & 160 & 54,79 & 80 & 27,39 \\
\hline 4 & $\mathrm{~F}$ & 61 & 36 & B & 1,55 & 125 & 52,08 & 62,5 & 26,04 \\
\hline 5 & $\mathrm{~F}$ & 33 & 59 & B & 1,56 & 131 & 53,90 & 74 & 30,45 \\
\hline 6 & $\mathrm{~F}$ & 55 & 88 & $\mathrm{~N}$ & 1,58 & 105 & 42,00 & 92 & 36,80 \\
\hline 7 & $\mathrm{~F}$ & 38 & 55 & B & 1,55 & 123 & 51,25 & 79 & 32,92 \\
\hline 8 & $\mathrm{~F}$ & 46 & 80 & B & 1,57 & 138 & 55,87 & 89 & 36,03 \\
\hline 9 & $\mathrm{~F}$ & 60 & 49 & B & 1,71 & 170 & 58,22 & 81 & 27,74 \\
\hline 10 & $\mathrm{~F}$ & 52 & 100 & B & 1,56 & 117 & 48,15 & 74 & 30,45 \\
\hline 11 & $\mathrm{~F}$ & 57 & 100 & $B$ & 1,64 & 118 & 43,87 & 78 & 28,99 \\
\hline 12 & $F$ & 56 & 74 & $B$ & 1,67 & 160 & 57,35 & 98 & 35,13 \\
\hline 13 & $\mathrm{~F}$ & 47 & 71 & B & 1,50 & 140 & 62,22 & 108 & 48,00 \\
\hline 14 & $M$ & 50 & 64 & $B$ & 1,82 & 180 & 54,39 & 122 & 36,86 \\
\hline 15 & $F$ & 32 & 92 & $P$ & 1,61 & 127 & 49,03 & 87 & 33,59 \\
\hline 16 & $F$ & 45 & 94 & $B$ & 1,57 & 164 & 66,80 & 120 & 48,58 \\
\hline 17 & $F$ & 27 & 65 & $B$ & 1,81 & 133 & 40,67 & 104 & 31,80 \\
\hline 18 & M & 43 & 90 & $B$ & 1,81 & 181 & 54,68 & 101 & 30,51 \\
\hline 19 & $\mathrm{~F}$ & 37 & 56 & $P$ & 1,51 & 105 & 46,05 & 65 & 28,50 \\
\hline 20 & $M$ & 47 & 77 & $B$ & 1,82 & 167 & 50,45 & 113 & 34,14 \\
\hline 21 & $\mathrm{~F}$ & 33 & 62 & $P$ & 1,80 & 168 & 51,85 & 70 & 21,60 \\
\hline 22 & $M$ & 42 & 76 & $B$ & 1,70 & 172 & 59,52 & 100 & 34,60 \\
\hline 23 & $\mathrm{~F}$ & 51 & 84 & $\mathrm{~N}$ & 1,48 & 105 & 47,94 & 72 & 32,87 \\
\hline 24 & $\mathrm{~F}$ & 22 & 77 & B & 1,75 & 198 & 64,70 & 118 & 38,56 \\
\hline 25 & $\mathrm{~F}$ & 51 & 73 & $B$ & 1,70 & 121 & 41,87 & 69 & 23,88 \\
\hline 26 & $F$ & 30 & 68 & $P$ & 1,56 & 130 & 53,50 & 71 & 29,22 \\
\hline 27 & $\mathrm{~F}$ & 33 & 75 & B & 1,55 & 140 & 58,33 & 80 & 33,33 \\
\hline 28 & $\mathrm{~F}$ & 33 & 88 & B & 1,60 & 120 & 46,86 & 65 & 25,39 \\
\hline 29 & $\mathrm{~F}$ & 40 & 62 & B & 1,55 & 200 & 83,33 & 75 & 31,25 \\
\hline 30 & $F$ & 48 & 84 & $B$ & 1,52 & 135 & 58,44 & 68 & 29,44 \\
\hline 31 & $\mathrm{~F}$ & 56 & 96 & $B$ & 1,58 & 135 & 54,00 & 97 & 38,80 \\
\hline 32 & $\mathrm{~F}$ & 42 & 102 & $B$ & 1,60 & 160 & 62,50 & 79 & 30,86 \\
\hline 33 & $\mathrm{~F}$ & 50 & 80 & $B$ & 1,61 & 140 & 54,06 & 62 & 23,94 \\
\hline 34 & $\mathrm{~F}$ & 46 & 134 & B & 1,60 & 150 & 58,59 & 135 & 52,73 \\
\hline 35 & $\mathrm{~F}$ & 51 & 91 & B & 1,52 & 126 & 54,56 & 87 & 37,66 \\
\hline 36 & $\mathrm{~F}$ & 41 & 102 & B & 1,68 & 150 & 53,19 & 100 & 35,46 \\
\hline 37 & $\mathrm{~F}$ & 57 & 79 & B & 1,65 & 160 & 58,82 & 100 & 36,76 \\
\hline 38 & $\mathrm{~F}$ & 54 & 97 & $B$ & 1,68 & 130 & 46,10 & 80 & 28,37 \\
\hline 39 & $M$ & 34 & 92 & $\mathrm{~N}$ & 1,88 & 148 & 39,36 & 134 & 35,64 \\
\hline 40 & $M$ & 31 & 69 & $B$ & 1,68 & 130 & 46,10 & 81 & 28,72 \\
\hline $\mathbf{M}$ & & 44,5 & 77,3 & & 1,63 & 142,6 & 53,32 & 88,03 & 32,86 \\
\hline
\end{tabular}

PO - Período pós-operatório no dia do procedimento endoscópico

PPO - Peso pré-operatório da cirurgia bariátrica

IMC PO - Índice de massa corpórea no pré-operatório da cirurgia bariátrica $\left(\mathrm{kg} / \mathrm{m}^{2}\right)$

M - Média 
Tabela Geral das Observações

\begin{tabular}{|c|c|c|c|c|c|c|}
\hline $\mathbf{N}$ & Disfagia & Anorexia & Emagrecimento & Anemia & HDA & Dor abdominal \\
\hline 1 & $\mathrm{n}$ & $\mathrm{n}$ & $\mathrm{n}$ & $\mathrm{n}$ & $\mathrm{n}$ & $\mathrm{n}$ \\
\hline 2 & $\mathrm{n}$ & $\mathrm{n}$ & $\mathrm{n}$ & $\mathrm{n}$ & $\mathrm{n}$ & $\mathrm{n}$ \\
\hline 3 & $\mathrm{n}$ & $\mathrm{n}$ & $\mathrm{n}$ & s & $\mathrm{n}$ & $\mathrm{n}$ \\
\hline 4 & $\mathrm{~s}$ & $\mathrm{n}$ & $\mathrm{n}$ & $\mathrm{s}$ & $\mathrm{n}$ & $\mathrm{n}$ \\
\hline 5 & $n$ & $\mathrm{n}$ & $\mathrm{n}$ & $\mathrm{s}$ & $\mathrm{n}$ & $\mathrm{n}$ \\
\hline 6 & $\mathrm{~s}$ & $\mathrm{n}$ & $\mathrm{n}$ & $\mathrm{n}$ & $\mathrm{n}$ & $\mathrm{s}$ \\
\hline 7 & $\mathrm{~s}$ & $\mathrm{n}$ & $\mathrm{n}$ & $\mathrm{n}$ & $\mathrm{n}$ & $\mathrm{n}$ \\
\hline 8 & $\mathrm{n}$ & $\mathrm{n}$ & $\mathrm{n}$ & $\mathrm{s}$ & $\mathrm{n}$ & $\mathrm{n}$ \\
\hline 9 & $\mathrm{n}$ & $\mathrm{n}$ & $\mathrm{n}$ & $\mathrm{n}$ & $\mathrm{n}$ & $\mathrm{n}$ \\
\hline 10 & $\mathrm{n}$ & $\mathrm{n}$ & $\mathrm{n}$ & $\mathrm{n}$ & $\mathrm{n}$ & $\mathrm{n}$ \\
\hline 11 & $\mathrm{n}$ & $\mathrm{n}$ & $\mathrm{n}$ & $\mathrm{n}$ & $\mathrm{n}$ & $\mathrm{n}$ \\
\hline 12 & $\mathrm{n}$ & $\mathrm{n}$ & $\mathrm{n}$ & $s$ & $\mathrm{n}$ & $\mathrm{n}$ \\
\hline 13 & $\mathrm{n}$ & $\mathrm{n}$ & $\mathrm{n}$ & $\mathrm{s}$ & $\mathrm{n}$ & $\mathrm{n}$ \\
\hline 14 & $\mathrm{n}$ & $\mathrm{n}$ & $\mathrm{n}$ & $n$ & $\mathrm{n}$ & $n$ \\
\hline 15 & $\mathrm{n}$ & $\mathrm{n}$ & $\mathrm{n}$ & $\mathrm{s}$ & $\mathrm{n}$ & $\mathrm{n}$ \\
\hline 16 & $\mathrm{n}$ & $\mathrm{n}$ & $\mathrm{n}$ & $\mathrm{s}$ & $\mathrm{n}$ & $\mathrm{n}$ \\
\hline 17 & $\mathrm{n}$ & $\mathrm{n}$ & $\mathrm{n}$ & $\mathrm{n}$ & $\mathrm{n}$ & $\mathrm{s}$ \\
\hline 18 & $\mathrm{n}$ & $\mathrm{n}$ & $\mathrm{n}$ & $n$ & $\mathrm{n}$ & $\mathrm{s}$ \\
\hline 19 & $\mathrm{n}$ & $\mathrm{n}$ & $\mathrm{n}$ & $\mathrm{s}$ & $\mathrm{n}$ & $\mathrm{n}$ \\
\hline 20 & $\mathrm{n}$ & $\mathrm{n}$ & $\mathrm{n}$ & $\mathrm{n}$ & $\mathrm{n}$ & $\mathrm{n}$ \\
\hline 21 & $\mathrm{n}$ & $\mathrm{n}$ & $\mathrm{n}$ & $\mathrm{s}$ & $n$ & $\mathrm{~s}$ \\
\hline 22 & $\mathrm{n}$ & $\mathrm{n}$ & $n$ & $n$ & $n$ & $n$ \\
\hline 23 & $\mathrm{n}$ & $\mathrm{n}$ & $n$ & $\mathrm{n}$ & $\mathrm{n}$ & $\mathrm{n}$ \\
\hline 24 & $\mathrm{n}$ & $\mathrm{n}$ & $\mathrm{n}$ & $\mathrm{s}$ & $n$ & $\mathrm{n}$ \\
\hline 25 & $\mathrm{n}$ & $\mathrm{n}$ & $\mathrm{n}$ & $\mathrm{n}$ & $\mathrm{n}$ & $\mathrm{n}$ \\
\hline 26 & $\mathrm{n}$ & $\mathrm{n}$ & $\mathrm{n}$ & $\mathrm{n}$ & $\mathrm{n}$ & $\mathrm{s}$ \\
\hline 27 & $\mathrm{n}$ & $\mathrm{n}$ & $\mathrm{n}$ & $n$ & $\mathrm{n}$ & $\mathrm{n}$ \\
\hline 28 & $\mathrm{n}$ & $\mathrm{n}$ & $\mathrm{n}$ & $\mathrm{n}$ & $\mathrm{n}$ & $\mathrm{n}$ \\
\hline 29 & $\mathrm{n}$ & $\mathrm{n}$ & $n$ & $n$ & $n$ & $\mathrm{n}$ \\
\hline 30 & $\mathrm{n}$ & $\mathrm{n}$ & $n$ & $n$ & $n$ & $\mathrm{n}$ \\
\hline 31 & $\mathrm{~s}$ & $\mathrm{~s}$ & $n$ & $n$ & $\mathrm{n}$ & $\mathrm{n}$ \\
\hline 32 & $\mathrm{n}$ & $\mathrm{n}$ & $\mathrm{n}$ & $n$ & $\mathrm{n}$ & $\mathrm{n}$ \\
\hline 33 & $\mathrm{n}$ & $\mathrm{n}$ & $\mathrm{n}$ & $\mathrm{s}$ & $n$ & $\mathrm{n}$ \\
\hline 34 & $\mathrm{n}$ & $\mathrm{n}$ & $\mathrm{n}$ & $\mathrm{s}$ & $\mathrm{n}$ & $\mathrm{s}$ \\
\hline 35 & $\mathrm{n}$ & $\mathrm{n}$ & $\mathrm{n}$ & $\mathrm{n}$ & $n$ & $\mathrm{~s}$ \\
\hline 36 & $\mathrm{n}$ & $\mathrm{n}$ & $\mathrm{n}$ & $\mathrm{n}$ & $\mathrm{n}$ & $\mathrm{n}$ \\
\hline 37 & $\mathrm{n}$ & $\mathrm{n}$ & $\mathrm{n}$ & $\mathrm{s}$ & $\mathrm{n}$ & $\mathrm{n}$ \\
\hline 38 & $\mathrm{n}$ & $\mathrm{n}$ & $\mathrm{n}$ & $\mathrm{s}$ & $\mathrm{n}$ & $\mathrm{n}$ \\
\hline 39 & $\mathrm{n}$ & $\mathrm{n}$ & $\mathrm{n}$ & $n$ & $n$ & $\mathrm{n}$ \\
\hline 40 & $\mathrm{n}$ & $\mathrm{n}$ & $\mathrm{n}$ & $\mathrm{n}$ & $\mathrm{n}$ & $\mathrm{n}$ \\
\hline
\end{tabular}

$\mathrm{s}$ - presente

$\mathrm{n}$ - ausente 
Tabela Geral das Observações

\begin{tabular}{|c|c|c|c|c|c|c|}
\hline $\mathbf{N}$ & Empachamento & Náusea & Vômito & Diarréia & Perda de Cabelo & Pirose \\
\hline 1 & $\mathrm{n}$ & $\mathrm{n}$ & $\mathrm{n}$ & $\mathrm{n}$ & $\mathrm{n}$ & $\mathrm{n}$ \\
\hline 2 & $\mathrm{n}$ & $n$ & $\mathrm{n}$ & $\mathrm{n}$ & $\mathrm{n}$ & $\mathrm{n}$ \\
\hline 3 & $\mathrm{~s}$ & $\mathrm{n}$ & $\mathrm{n}$ & $\mathrm{n}$ & $\mathrm{s}$ & $\mathrm{n}$ \\
\hline 4 & $\mathrm{n}$ & $\mathrm{n}$ & $\mathrm{n}$ & $\mathrm{n}$ & $\mathrm{s}$ & $\mathrm{s}$ \\
\hline 5 & $\mathrm{~s}$ & $\mathrm{n}$ & $\mathrm{s}$ & $\mathrm{n}$ & $\mathrm{s}$ & $s$ \\
\hline 6 & $\mathrm{~s}$ & $\mathrm{~s}$ & $\mathrm{~s}$ & $n$ & $\mathrm{~s}$ & $s$ \\
\hline 7 & $\mathrm{n}$ & $\mathrm{n}$ & $\mathrm{n}$ & $n$ & $\mathrm{~s}$ & $\mathrm{n}$ \\
\hline 8 & $\mathrm{n}$ & $\mathrm{n}$ & $\mathrm{n}$ & $\mathrm{n}$ & $\mathrm{s}$ & $n$ \\
\hline 9 & $\mathrm{n}$ & $\mathrm{n}$ & $\mathrm{n}$ & $\mathrm{n}$ & $\mathrm{n}$ & $s$ \\
\hline 10 & $\mathrm{n}$ & $\mathrm{n}$ & $\mathrm{n}$ & $\mathrm{n}$ & $\mathrm{n}$ & $\mathrm{n}$ \\
\hline 11 & $\mathrm{n}$ & $\mathrm{n}$ & $\mathrm{n}$ & $\mathrm{n}$ & $\mathrm{n}$ & $\mathrm{S}$ \\
\hline 12 & $\mathrm{~s}$ & $\mathrm{n}$ & $\mathrm{s}$ & $\mathrm{n}$ & $\mathrm{n}$ & $\mathrm{n}$ \\
\hline 13 & $\mathrm{~s}$ & $\mathrm{~s}$ & $\mathrm{~S}$ & $\mathrm{~s}$ & $\mathrm{n}$ & $\mathrm{n}$ \\
\hline 14 & $\mathrm{n}$ & $\mathrm{n}$ & $\mathrm{n}$ & $n$ & $\mathrm{n}$ & $\mathrm{s}$ \\
\hline 15 & $\mathrm{n}$ & $\mathrm{n}$ & $\mathrm{n}$ & $\mathrm{n}$ & $\mathrm{s}$ & $n$ \\
\hline 16 & $\mathrm{n}$ & $\mathrm{n}$ & $\mathrm{n}$ & $\mathrm{n}$ & $\mathrm{n}$ & $\mathrm{n}$ \\
\hline 17 & $\mathrm{n}$ & $\mathrm{n}$ & $\mathrm{n}$ & $\mathrm{n}$ & $\mathrm{n}$ & $\mathrm{s}$ \\
\hline 18 & $\mathrm{n}$ & $\mathrm{n}$ & $\mathrm{n}$ & $\mathrm{s}$ & $\mathrm{n}$ & $n$ \\
\hline 19 & $\mathrm{~s}$ & $\mathrm{n}$ & $\mathrm{s}$ & $\mathrm{n}$ & $\mathrm{s}$ & $\mathrm{s}$ \\
\hline 20 & $\mathrm{n}$ & $\mathrm{n}$ & $\mathrm{n}$ & $\mathrm{n}$ & $\mathrm{n}$ & $\mathrm{n}$ \\
\hline 21 & $\mathrm{~s}$ & $\mathrm{n}$ & $\mathrm{s}$ & $\mathrm{s}$ & $\mathrm{n}$ & $s$ \\
\hline 22 & $\mathrm{n}$ & $\mathrm{n}$ & $\mathrm{n}$ & $\mathrm{n}$ & $\mathrm{s}$ & $s$ \\
\hline 23 & $\mathrm{n}$ & $\mathrm{n}$ & $\mathrm{n}$ & $n$ & $\mathrm{n}$ & $\mathrm{n}$ \\
\hline 24 & $\mathrm{n}$ & $\mathrm{n}$ & $\mathrm{n}$ & $\mathrm{n}$ & $\mathrm{n}$ & $\mathrm{n}$ \\
\hline 25 & $\mathrm{n}$ & $\mathrm{n}$ & $\mathrm{n}$ & $n$ & $\mathrm{n}$ & $\mathrm{n}$ \\
\hline 26 & $\mathrm{~s}$ & $\mathrm{n}$ & $\mathrm{n}$ & $\mathrm{n}$ & $\mathrm{n}$ & $\mathrm{s}$ \\
\hline 27 & $\mathrm{n}$ & $\mathrm{n}$ & $\mathrm{s}$ & $\mathrm{n}$ & $\mathrm{n}$ & $n$ \\
\hline 28 & $\mathrm{n}$ & $\mathrm{n}$ & $\mathrm{n}$ & $\mathrm{n}$ & $\mathrm{n}$ & $s$ \\
\hline 29 & $\mathrm{n}$ & $\mathrm{n}$ & $\mathrm{n}$ & $\mathrm{n}$ & $\mathrm{n}$ & $\mathrm{n}$ \\
\hline 30 & $\mathrm{n}$ & $\mathrm{n}$ & $\mathrm{n}$ & $\mathrm{s}$ & $\mathrm{n}$ & $\mathrm{n}$ \\
\hline 31 & $\mathrm{~s}$ & $\mathrm{n}$ & $\mathrm{n}$ & $\mathrm{n}$ & $\mathrm{s}$ & $\mathrm{n}$ \\
\hline 32 & $\mathrm{n}$ & $\mathrm{n}$ & $\mathrm{n}$ & $n$ & $n$ & $n$ \\
\hline 33 & $\mathrm{n}$ & $\mathrm{n}$ & $\mathrm{n}$ & $\mathrm{n}$ & $\mathrm{n}$ & $\mathrm{n}$ \\
\hline 34 & $\mathrm{n}$ & $\mathrm{n}$ & $\mathrm{n}$ & $\mathrm{n}$ & $\mathrm{s}$ & $\mathrm{n}$ \\
\hline 35 & $\mathrm{n}$ & $\mathrm{n}$ & $\mathrm{n}$ & $\mathrm{n}$ & $\mathrm{n}$ & $\mathrm{s}$ \\
\hline 36 & $\mathrm{~s}$ & $\mathrm{n}$ & $\mathrm{n}$ & $\mathrm{n}$ & $\mathrm{n}$ & $n$ \\
\hline 37 & $\mathrm{n}$ & $\mathrm{n}$ & $\mathrm{n}$ & $\mathrm{n}$ & $\mathrm{n}$ & $\mathrm{s}$ \\
\hline 38 & $\mathrm{n}$ & $\mathrm{n}$ & $\mathrm{n}$ & $\mathrm{n}$ & $\mathrm{n}$ & $\mathrm{n}$ \\
\hline 39 & $\mathrm{n}$ & $\mathrm{n}$ & $\mathrm{n}$ & $\mathrm{n}$ & $\mathrm{s}$ & $\mathrm{n}$ \\
\hline 40 & $\mathrm{n}$ & $\mathrm{n}$ & $\mathrm{n}$ & $\mathrm{n}$ & $\mathrm{s}$ & $\mathrm{n}$ \\
\hline
\end{tabular}


Tabela Geral das Observações

\begin{tabular}{|c|c|c|c|c|c|c|c|}
\hline $\mathbf{N}$ & $\begin{array}{c}\Delta t \\
\text { estômago } \\
\text { (minutos) }\end{array}$ & $\begin{array}{l}\Delta t \text { exame } \\
\text { (minutos) }\end{array}$ & Radioscopia & $\begin{array}{c}\text { Midazolan } \\
(\mathrm{mg})\end{array}$ & $\begin{array}{c}\begin{array}{c}\text { Fentanila } \\
(\mathrm{mcg})\end{array} \\
\end{array}$ & $\begin{array}{c}\text { Propofol } \\
(\mathrm{mg})\end{array}$ & $\begin{array}{c}\text { Escopolamina } \\
(\mathrm{mg})\end{array}$ \\
\hline 1 & 20 & 30 & $\operatorname{sim}$ & 5 & 50 & 50 & 0 \\
\hline 2 & 30 & 45 & $\operatorname{sim}$ & 5 & 50 & 60 & 0 \\
\hline 3 & 60 & 75 & $\operatorname{sim}$ & 7 & 70 & 600 & 20 \\
\hline 4 & 18 & 44 & $\operatorname{sim}$ & 5 & 50 & 90 & 20 \\
\hline 5 & 11 & 36 & não & 7 & 50 & 150 & 20 \\
\hline 6 & 75 & 90 & $\operatorname{sim}$ & 10 & 50 & 200 & 20 \\
\hline 7 & 25 & 40 & $\operatorname{sim}$ & 5 & 50 & 150 & 20 \\
\hline 8 & 22 & 45 & sim & 10 & 50 & 300 & 20 \\
\hline 9 & NA & NA & $\operatorname{sim}$ & NA & NA & NA & NA \\
\hline 10 & 20 & 35 & sim & 7 & 50 & 50 & 20 \\
\hline 11 & 18 & 33 & sim & 7 & 100 & 250 & 40 \\
\hline 12 & NA & NA & $\operatorname{sim}$ & NA & NA & NA & NA \\
\hline 13 & 37 & 52 & não & 15 & 100 & 600 & 20 \\
\hline 14 & NA & NA & não & NA & NA & NA & NA \\
\hline 15 & 20 & 35 & sim & 5 & 80 & 500 & 20 \\
\hline 16 & 18 & 35 & não & 5 & 50 & 250 & 20 \\
\hline 17 & 14 & 29 & não & 5 & 50 & 250 & 20 \\
\hline 18 & 17 & 38 & não & 10 & 100 & 150 & 20 \\
\hline 19 & 28 & 43 & não & 8 & 100 & 400 & 20 \\
\hline 20 & 20 & 35 & não & 5 & 50 & 160 & 20 \\
\hline 21 & 36 & 50 & não & 5 & 75 & 400 & 60 \\
\hline 22 & 53 & 68 & não & 5 & 75 & 380 & 80 \\
\hline 23 & 21 & 34 & não & 5 & 75 & 400 & 60 \\
\hline 24 & 22 & 37 & não & 5 & 75 & 400 & 20 \\
\hline 25 & 13 & 28 & não & 5 & 50 & 140 & 20 \\
\hline 26 & 22 & 37 & não & 5 & 50 & 250 & 30 \\
\hline 27 & 13 & 28 & não & 5 & 50 & 250 & 20 \\
\hline 28 & 22 & 37 & não & 5 & 50 & 260 & 60 \\
\hline 29 & 20 & 35 & não & 5 & 50 & 600 & 40 \\
\hline 30 & 5 & 20 & não & 5 & 50 & 300 & 40 \\
\hline 31 & 15 & 30 & não & 5 & 50 & 200 & 40 \\
\hline 32 & NA & NA & não & NA & NA & NA & NA \\
\hline 33 & 22 & 37 & não & 5 & 50 & 200 & 20 \\
\hline 34 & 10 & 25 & não & 5 & 50 & 250 & 20 \\
\hline 35 & 22 & 37 & não & 15 & 50 & 300 & 40 \\
\hline 36 & 40 & 55 & não & 8 & 80 & 400 & 40 \\
\hline 37 & 35 & 50 & não & 5 & 50 & 400 & 40 \\
\hline 38 & NA & NA & não & NA & NA & NA & NA \\
\hline 39 & 16 & 31 & não & 10 & 40 & 250 & 20 \\
\hline 40 & 31 & 46 & não & 10 & 50 & 250 & 2 \\
\hline $\mathbf{M}$ & 24,9 & 40,7 & & 6,7 & 60,6 & 281,1 & 27,8 \\
\hline
\end{tabular}

$\Delta$ t estômago - Tempo decorrido até se alcançar o estômago excluso $\Delta$ t exame - Tempo total de exame

$\mathrm{mg}$ - Miligramas

NA - Não avaliado

M - Média 
Tabela Geral das Observações

\begin{tabular}{|c|c|c|c|c|c|c|c|}
\hline $\mathbf{N}$ & Esôfago & $\begin{array}{l}\text { TEG } \\
(\mathbf{c m})\end{array}$ & $\begin{array}{c}\text { Coto } \\
\text { gástrico } \\
\text { proximal }\end{array}$ & $\begin{array}{l}\text { Coto gástrico } \\
\text { proximal }(\mathrm{cm})\end{array}$ & Anel & $\begin{array}{l}\text { Anastomose } \\
\text { gastrojejunal }\end{array}$ & $\begin{array}{c}\text { Alça } \\
\text { jejunal }\end{array}$ \\
\hline 1 & normal & 38 & normal & 4 & não (e) & normal & normal \\
\hline 2 & normal & 37 & normal & 6 & $\operatorname{sim}$ & normal & normal \\
\hline 3 & normal & 40 & enantema & 7 & não (c) & normal & normal \\
\hline 4 & normal & 36 & normal & 7 & $\operatorname{sim}$ & úlcera jejunal & normal \\
\hline 5 & normal & 36 & normal & 5 & $\operatorname{sim}$ & normal & normal \\
\hline 6 & $A$ & 32 & normal & 4 & $\operatorname{sim}$ & normal & normal \\
\hline 7 & ENE & 40 & normal & 6 & $\operatorname{sim}$ & normal & normal \\
\hline 8 & normal & 38 & normal & 6 & $\operatorname{sim}$ & normal & normal \\
\hline 9 & normal & 41 & normal & 7 & $\operatorname{sim}$ & normal & normal \\
\hline 10 & normal & 35 & normal & 6 & sim & $\begin{array}{l}\text { erosões } \\
\text { jejunais }\end{array}$ & normal \\
\hline 11 & A & 40 & normal & 7 & $\operatorname{sim}$ & normal & normal \\
\hline 12 & normal & 38 & normal & 5 & $\operatorname{sim}$ & normal & normal \\
\hline 13 & normal & 39 & normal & 4 & $\operatorname{sim}$ & normal & normal \\
\hline 14 & B & 41 & normal & 8 & $\operatorname{sim}(m)$ & normal & normal \\
\hline 15 & normal & 36 & normal & 5 & $\operatorname{sim}$ & normal & normal \\
\hline 16 & normal & 39 & normal & 6 & não (c) & normal & normal \\
\hline 17 & normal & 40 & normal & 5 & $\operatorname{sim}(m)$ & normal & normal \\
\hline 18 & normal & 40 & normal & 4 & não (c) & normal & normal \\
\hline 19 & normal & 39 & normal & 4 & $\operatorname{sim}$ & normal & normal \\
\hline 20 & $B$ & 40 & normal & 5 & $\operatorname{sim}(m)$ & normal & normal \\
\hline 21 & normal & 38 & normal & 5 & $\operatorname{sim}$ & normal & normal \\
\hline 22 & A & 41 & normal & 6 & $\operatorname{sim}$ & normal & normal \\
\hline 23 & normal & 33 & normal & 7 & $\operatorname{sim}(m)$ & normal & normal \\
\hline 24 & normal & 42 & normal & 4 & $\operatorname{sim}(m)$ & normal & normal \\
\hline 25 & normal & 44 & normal & 5 & $\operatorname{sim}$ & normal & normal \\
\hline 26 & $A$ & 37 & normal & 5 & $\operatorname{sim}$ & normal & normal \\
\hline 27 & normal & 40 & normal & 6 & $\operatorname{sim}$ & normal & normal \\
\hline 28 & normal & 35 & normal & 6 & $\operatorname{sim}$ & normal & normal \\
\hline 29 & normal & 37 & normal & 5 & $\operatorname{sim}$ & normal & normal \\
\hline 30 & normal & 35 & normal & 6 & $\operatorname{sim}$ & normal & normal \\
\hline 31 & normal & 35 & normal & 7 & $\operatorname{sim}$ & normal & normal \\
\hline 32 & $B$ & 37 & normal & 6 & $\operatorname{sim}(m)$ & normal & normal \\
\hline 33 & normal & 38 & normal & 6 & $\operatorname{sim}$ & úlcera jejunal & normal \\
\hline 34 & normal & 36 & normal & 5 & não (c) & normal & normal \\
\hline 35 & normal & 39 & normal & 4 & $\operatorname{sim}$ & normal & normal \\
\hline 36 & normal & 36 & normal & 6 & $\operatorname{sim}$ & normal & normal \\
\hline 37 & ENE & 40 & normal & 5 & $\operatorname{sim}$ & normal & normal \\
\hline 38 & normal & 40 & normal & 7 & $\operatorname{sim}$ & normal & normal \\
\hline 39 & normal & 41 & normal & 6 & $\operatorname{sim}$ & normal & normal \\
\hline 40 & normal & 38 & normal & 5 & $\operatorname{sim}$ & normal & normal \\
\hline $\mathbf{M}$ & & 38,2 & & 5,6 & & & \\
\hline
\end{tabular}

TEG - Transição esofagogástrica

ENE - Esofagite não erosiva

A - Esofagite erosiva grau A de Los Angeles

$B$ - Esofagite erosiva grau $B$ de Los Angeles

Não (e) - Sem o anel de contenção, retirado por endoscopia

Não (c) - Sem o anel de contenção, retirado por cirurgia

Sim $(\mathrm{m})$ - Com o anel de contenção, porém migrado para a luz

$\mathrm{M}$ - Média 
Tabela Geral das Observações

\begin{tabular}{|c|c|c|c|c|c|c|}
\hline $\mathbf{N}$ & $\begin{array}{c}\text { Anastomose } \\
\mathrm{J}-\mathrm{J}\end{array}$ & Duodeno & $\begin{array}{c}\text { Estômago } \\
\text { Excluso - } \\
\text { Piloro }\end{array}$ & $\begin{array}{c}\text { Estômago } \\
\text { Excluso - } \\
\text { Lago mucoso }\end{array}$ & \begin{tabular}{|c|} 
Estômago \\
Excluso - \\
Fundo/Corpo
\end{tabular} & $\begin{array}{c}\text { Estômago } \\
\text { Excluso - } \\
\text { Antro }\end{array}$ \\
\hline 1 & término-lateral & normal & normal & claro & enantema & enantema \\
\hline 2 & término-lateral & normal & normal & claro & atrofia & atrofia \\
\hline 3 & término-lateral & normal & normal & bilioso grande & atrofia & atrofia $+\mathrm{Ml}$ \\
\hline 4 & término-lateral & erosões & normal & claro & erosões (h) & erosões $(h)$ \\
\hline 5 & término-lateral & normal & normal & bilioso grande & erosões & erosões \\
\hline 6 & látero-lateral & normal & normal & bilioso grande & atrofia & atrofia $+\mathrm{Ml}$ \\
\hline 7 & látero-lateral & normal & normal & bilioso grande & enantema & enantema \\
\hline 8 & término-lateral & normal & normal & bilioso pequeno & enantema & enantema \\
\hline 9 & término-lateral & $\mathrm{NA}$ & NA & NA & NA & NA \\
\hline 10 & término-lateral & normal & normal & bilioso pequeno & erosões $(h)$ & erosões (h) \\
\hline 11 & término-lateral & normal & normal & bilioso grande & erosões & erosões \\
\hline 12 & término-lateral & NA & NA & NA & NA & NA \\
\hline 13 & término-lateral & normal & normal & bilioso grande & atrofia & atrofia \\
\hline 14 & NA & NA & NA & NA & NA & NA \\
\hline 15 & término-lateral & normal & normal & claro & normal & normal \\
\hline 16 & látero-lateral & normal & normal & bilioso grande & enantema & enantema \\
\hline 17 & término-lateral & normal & normal & bilioso grande & normal & normal \\
\hline 18 & látero-lateral & normal & normal & bilioso grande & enantema & enantema \\
\hline 19 & término-lateral & normal & normal & bilioso grande & enantema & enantema \\
\hline 20 & término-lateral & normal & normal & bilioso pequeno & enantema & enantema \\
\hline 21 & término-lateral & normal & normal & bilioso pequeno & normal & normal \\
\hline 22 & término-lateral & normal & normal & bilioso pequeno & enantema & enantema \\
\hline 23 & látero-lateral & normal & normal & claro & atrofia & atrofia \\
\hline 24 & término-lateral & normal & normal & bilioso grande & erosões & erosões \\
\hline 25 & látero-lateral & normal & normal & claro & normal & normal \\
\hline 26 & término-lateral & erosões & normal & bilioso grande & erosões & erosões \\
\hline 27 & término-lateral & normal & normal & claro & normal & normal \\
\hline 28 & término-lateral & normal & normal & bilioso pequeno & normal & normal \\
\hline 29 & látero-lateral & normal & normal & bilioso grande & enantema & enantema \\
\hline 30 & término-lateral & normal & normal & claro & enantema & enantema \\
\hline 31 & látero-lateral & normal & normal & claro & normal & normal \\
\hline 32 & término-lateral & $\mathrm{NA}$ & NA & NA & NA & NA \\
\hline 33 & látero-lateral & normal & normal & bilioso grande & atrofia & atrofia \\
\hline 34 & látero-lateral & normal & normal & bilioso grande & erosões (h) & erosões (h) \\
\hline 35 & látero-lateral & normal & normal & claro & erosões (h) & erosões $(h)$ \\
\hline 36 & término-lateral & normal & normal & claro & normal & normal \\
\hline 37 & látero-lateral & normal & normal & bilioso pequeno & erosões & erosões \\
\hline 38 & estenose & NA & NA & NA & NA & NA \\
\hline 39 & látero-lateral & normal & normal & bilioso grande & erosões (h) & erosões $(h)$ \\
\hline 40 & término-lateral & normal & normal & bilioso pequeno & normal & normal \\
\hline
\end{tabular}


Tabela Geral das Observações

\begin{tabular}{|c|c|c|c|c|c|c|}
\hline $\mathbf{N}$ & $\begin{array}{l}\text { AP Coto } \\
\text { gástrico } \\
\text { proximal }\end{array}$ & $\begin{array}{l}\text { Hp Coto } \\
\text { gástrico } \\
\text { proximal }\end{array}$ & $\begin{array}{c}\text { Estômago } \\
\text { Excluso AP } \\
\text { fundo/corpo }\end{array}$ & $\begin{array}{c}\text { Estômago } \\
\text { Excluso } \\
\text { Hp fundo/corpo }\end{array}$ & $\begin{array}{c}\text { Estômago } \\
\text { Excluso } \\
\text { AP antro }\end{array}$ & $\begin{array}{c}\text { Estômago } \\
\text { Excluso } \\
\text { Hp antro }\end{array}$ \\
\hline 1 & GCA & positivo & GAMI & negativo & $\mathrm{GCl}$ & negativo \\
\hline 2 & $\mathrm{GCl}$ & negativo & $\mathrm{GCl}$ & negativo & $\mathrm{GCl}$ & negativo \\
\hline 3 & $\mathrm{GCl}$ & negativo & GAMI & negativo & GAMI & negativo \\
\hline 4 & $\mathrm{GCl}$ & negativo & $\mathrm{GCl}$ & negativo & $\mathrm{GCl}$ & negativo \\
\hline 5 & $\mathrm{GCl}$ & negativo & $\mathrm{GCl}$ & negativo & $\mathrm{GCl}$ & negativo \\
\hline 6 & $\mathrm{GCl}$ & negativo & GAMI & negativo & GAMI & negativo \\
\hline 7 & GCA & positivo & GCA & positivo & GCA & positivo \\
\hline 8 & $\mathrm{GCl}$ & positivo & $\mathrm{GCl}$ & negativo & $\mathrm{GCl}$ & positivo \\
\hline 9 & NA & $\mathrm{NA}$ & NA & NA & NA & NA \\
\hline 10 & $\mathrm{GCl}$ & negativo & $\mathrm{GCl}$ & negativo & $\mathrm{GCl}$ & negativo \\
\hline 11 & $\mathrm{GCl}$ & negativo & $\mathrm{GCl}$ & positivo & $\mathrm{GCl}$ & positivo \\
\hline 12 & NA & NA & NA & NA & NA & NA \\
\hline 13 & $\mathrm{GCl}$ & negativo & GAMI & negativo & GCA & negativo \\
\hline 14 & NA & NA & NA & NA & NA & NA \\
\hline 15 & $\mathrm{GCl}$ & negativo & $\mathrm{GCl}$ & negativo & $\mathrm{NL}$ & negativo \\
\hline 16 & $\mathrm{GCl}$ & negativo & $\mathrm{GCl}$ & negativo & $\mathrm{GCl}$ & negativo \\
\hline 17 & $\mathrm{GCl}$ & negativo & $\mathrm{GCl}$ & negativo & $\mathrm{GCl}$ & negativo \\
\hline 18 & GCA & positivo & GA & negativo & GCA & positivo \\
\hline 19 & GCA & positivo & $\mathrm{GCl}$ & negativo & $\mathrm{GCl}$ & positivo \\
\hline 20 & $\mathrm{GCl}$ & negativo & $\mathrm{GCl}$ & negativo & $\mathrm{GCl}$ & negativo \\
\hline 21 & $\mathrm{GCl}$ & negativo & GCA & negativo & $\mathrm{GCl}$ & negativo \\
\hline 22 & $\mathrm{GCl}$ & negativo & $\mathrm{GCl}$ & negativo & $\mathrm{GCl}$ & negativo \\
\hline 23 & GCA & positivo & GCA & negativo & $\mathrm{GCl}$ & negativo \\
\hline 24 & $\mathrm{GCl}$ & negativo & $\mathrm{GCl}$ & negativo & $\mathrm{GCl}$ & negativo \\
\hline 25 & $\mathrm{GCl}$ & positivo & $\mathrm{GCl}$ & negativo & $\mathrm{GCl}$ & negativo \\
\hline 26 & $\mathrm{GCl}$ & negativo & $\mathrm{NL}$ & negativo & $\mathrm{GCl}$ & negativo \\
\hline 27 & $\mathrm{GCl}$ & negativo & $\mathrm{GCl}$ & negativo & $\mathrm{GCl}$ & negativo \\
\hline 28 & $\mathrm{GCl}$ & negativo & $\mathrm{GCl}$ & negativo & $\mathrm{GCl}$ & negativo \\
\hline 29 & GCA & positivo & $\mathrm{GCl}$ & negativo & $\mathrm{GCl}$ & negativo \\
\hline 30 & GCA & positivo & GCA & positivo & GCA & positivo \\
\hline 31 & $\mathrm{GCl}$ & negativo & $\mathrm{GCl}$ & negativo & $\mathrm{GCl}$ & negativo \\
\hline 32 & NA & NA & NA & NA & NA & NA \\
\hline 33 & $\mathrm{GCl}$ & negativo & $\mathrm{GCl}$ & negativo & $\mathrm{GCl}$ & negativo \\
\hline 34 & $\mathrm{GCl}$ & positivo & $\mathrm{GCl}$ & positivo & $\mathrm{GCl}$ & positivo \\
\hline 35 & $\mathrm{GCl}$ & negativo & $\mathrm{GCl}$ & negativo & $\mathrm{GCl}$ & negativo \\
\hline 36 & $\mathrm{GCl}$ & negativo & $\mathrm{GCl}$ & negativo & $\mathrm{GCl}$ & negativo \\
\hline 37 & $\mathrm{GCl}$ & negativo & $\mathrm{GCl}$ & negativo & $\mathrm{GCl}$ & negativo \\
\hline 38 & NA & NA & NA & NA & NA & NA \\
\hline 39 & GCA & positivo & $\mathrm{GCl}$ & negativo & $\mathrm{GCl}$ & negativo \\
\hline 40 & $\mathrm{GCl}$ & negativo & $\mathrm{GCl}$ & negativo & $\mathrm{GCl}$ & negativo \\
\hline
\end{tabular}

AP - Anatomopatológico

$\mathrm{Hp}$ - Helicobacter pylori

$\mathrm{GCl}$ - Gastrite crônica inativa

GCA - Gastrite crônica ativa

GA - Gastrite atrófica

GAMI - Gastrite atrófica com metaplasia intestinal

$\mathrm{NL}$ - Sem anormalidades histológicas 
10. REFERÊNCIAS 
1. National Institutes of Health: Implications of obesity. National Institutes of Health Consensus Development Conference Statement. Ann Intern Med 1995; 103:1073-1077.

2. Bray GA. Definition, measurement and classification of the syndromes of obesity. Int J Obes 1978; 2:99-112.

3. National Institutes of Health, National Heart, Lung, and Blood Institute. Clinical guidelines on the identification, evaluation, and treatment of overweight and obesity in adults: the evidence report. Obesity Res 1998; Suppl2:S51-S209.

4. Pesquisa de Orçamentos Familiares POF 2002-2003. Análise da disponibilidade Domiciliar de Alimentos e do Estado Nutricional no Brasil. IBGE, 2004.

5. Hacker DC, Deitel M. The etiology of obesity. Obes Surg 1991; 1:21-27.

6. Wooley SC, Garner DM. Dietary treatments for obesity are ineffective. British Med J 1994; 309:655-656.

7. Deitel M. Overview of operations for morbid obesity. World J Surg 1998; 22:913-918.

8. Ministério da Saúde - Portaria número 196 de 29/02/2000. Diário Oficial da União, 01/03/2000. 
9. Capella RF, Capella JF, Mandac H, Nath P. Vertical banded gastroplasty - Gastric bypass: preliminary report. Obes Surg 1991; 1:389-395.

10. Yamamoto H, Sugano K. A new method of enteroscopy - The doubleballon method. Can J Gastroenterol 2003; 17:273-274.

11. Yamamoto H, Yano T, Kita H, Sunada K, Ido K, Sugano K. New system of double-balloon enteroscopy for diagnosis and treatment of small intestinal disorders. Gastroenterology 2003; 125:1556-1557.

12. Kremen AJ, Linner $\mathrm{JH}$, Nelson $\mathrm{CH}$. An experimental evaluation of the nutritional importance of proximal and distal small intestine. Ann Surg $1954 ; 140: 439-443$.

13. Payne JH, DeWind LT. Surgical treatment of obesity. Am J Surg 1969; 118:141-147.

14. Lewis LA, Turnbull RB Jr, Page IH. Effects of jejuno colic shunt for obesity serum lipoproteins, lipids and eletrolytes. Arch Intern Med 1966; 117: 4-16.

15. Mason EE, Ito C. Gastric bypass in obesity. Surg Clin North Am 1967; $47: 1345-1352$.

16. Mason EE, Printen KJ, Bloomers TJ. Gastric bypass for obesity after ten years experience. Int J Obes 1978; 2:197-205.

17. Griffen WO Jr., Young VL, Stevenson CC. A prospective comparison of gastric and jejunoileal bypass procedures for morbid obesity. Ann Surg 1977; 186:500-505.

18. Scopionaro N, Gianetta E, Civalerri D, et al. Biliopancreatic bypass for obesity: II. Initial experience in man. Br J Surg 1979; 66:618-620. 
19. Mason EE. Vertical banded gastroplasty for obesity. Arch Surg 1982; 117:701-706.

20. Hess DW, Hess DS. Biliopancreatic diversion with duodenal switch. Obes Surg 1998; 8:267-282.

21. Marceau P, Hould FS, Simard S, Lebel S, Bourque RA, Potvin M, Biron S. Biliopancreatic diversion with duodenal switch. World J Surg 1998; 22:947-954.

22. Fobi MAL, Fleming AW. Vertical banded gastroplasty versus gastric bypass in the treatment of obesity. J Natl Med Assoc 1986; 78:1092-1098.

23. Fobi MAL, Lee $H$, Holness $R$, Cabinda $D$. Gastric bypass operation for obesity. World J Surg 1998; 22:925-935.

24. Fobi MAL, Lee $\mathrm{H}$. The surgical technique of the Fobi-Pouch operation for obesity (The transected silastic vertical gastric bypass). Obes Surg 1998; 8:283-288.

25. Capella RF, Capella JF, Mandac H, Nath P. Vertical banded gastroplasty-gastric bypass: preliminary report. Obes Surg 1991; 1:389-395.

26. Garrido AB Jr, Oliveira MR, Berti LV, Elias AA, Pareja JC, Matsuda M, Gama-Rodrigues JJ. Derivações gastrojejunais. In: Garrido AB Jr. Cirurgia da Obesidade. São Paulo Editora Atheneu; 2002. p.155-62.

27. Wittgrove AC, Clark GW. Laparoscopic gastric bypass, Roux-en-Y technique and results in 75 patients with 3-30 months follow-up. Obes Surg 1996; 6:500-504. 
28. Yamamoto $H$, Sekine $Y$, Sato $Y$, Higashizawa $T$, Miyata $T$, lino $S$, Ido $K$, Sugano K. Total enteroscopy with a nonsurgical steerable boubleballoon method. Gastrointest Endosc 2001; 53:216-220.

29. Yamamoto H, Sugano K. A new method of enteroscopy - The double balloon method. Can J Gastroenterol 2003; 17:273-74.

30. May A, Nachbar L, Wardak A, Yamamoto H, Ell C. Double-balloon enteroscopy: preliminary experience in patients with obscure gastrointestinal bleeding and chronic abdominal pain. Endoscopy 2003; 35:985-981.

31. Yamamoto $H$, Kita $H$, Sunada $K$, Hayashi $Y$, Sato $H$, Yano $T$, Iwamoto M, Sekine Y, Miyata T, Kuno A, Ajibe H, Ido K, Sugano K. Clinical outcomes of double-balloon endoscopy for the diagnosis and treatment of small-intestinal diseases. Clin Gastroenterol Hepatol 2004; 2:1010-1016.

32. Strodel WE, Knol JA, Eckhauser FE. Endoscopy of the partioned stomach. Ann Surg 1984; 200:582-586.

33. Flickinger EG, Sinar DR, Pories WJ, Sloss RR, Park HK, Gibson JH. The bypassed stomach. Am J Surg 1985; 149:151-156.

34. Sinar DR, Flickinger EG, Park HK, Sloss RR. Retrograde endoscopy of the bypassed stomach segment after gastric bypass surgery: unexpected lesions. South Med J 1985; 78:255-258.

35. Flickinger EG, Pories WJ, Meelheim DH, Sinar DR, Blose IL, Thomas FT. The Greenville gastric bypass: Progress report after 3 years. Ann Surg 1984; 199:555-62. 
36. McNelly GF, Stork JJ, Macgregor AMC, Burns EW. Percutaneous examination of the bypassed stomach. Obes Surg 1991; 1:427-430.

37. Fobi MAL, Chicola K, Lee H. Access to the bypassed stomach after gastric bypass. Obes Surg 1998; 8:289-295.

38. Sundbom M, Nyman R, Hedenström H, Gustavsson S. Investigation of the excluded stomach after Roux-en-Y gastric bypass. Obes Surg 2001; $11: 25-27$.

39. Silecchia G, Catalano C, Gentileschi P, Elmore U, Restuccia A, Gagner M, Basso N. Virtual gastroduodenoscopy: a new look at the bypassed stomach and duodenum after laparoscopic Roux-en-Y gastric bypass for morbid obesity. Obes Surg 2002; 12:39-48.

40. Sakai P, Kuga R, Safatle-Ribeiro AV, Faintuch J, Gama-Rodrigues JJ, Ishida RK, Furuya Jr. CK, Yamamoto H, Ishioka S. Is it feasible to reach the bypassed stomach after Roux-en-Y gastric bypass for morbid obesity? The use of the double-balloon enteroscope. Endoscopy 2005; 37:566-569.

41. Ishida RK, Faintuch J, Paula AMR, Risttori CA, Silva SN, Gomes ES, Mattar R, Kuga R, Ribeiro AS, Sakai P, Barbeiro HV, Barbeiro DF, Soriano FG, Cecconello I. Microbial flora of the stomach after gastric bypass for morbid obesity. Obes Surg 2007; 17:752-8.

42. Goodwin CS, Armstrong JA. Microbiological aspects of Helicobacter pylori (Campilobacter pylori). Eur J Clin Microbiol Infect Dis 1990;9:1-13.

43. Valle C, Bizinelli SL. Prevalência do Helicobacter pylori em pacientes submetidos a endoscopia digestiva alta. Rev Méd Paraná 1993;50:17-20.

44. Dixon MF. Pathophysiology of Helicobacter pylori infection. Scand J Gastroenterol 1994; 29(Suppl 201):7-10. 
45. Cutler AF, Havstad S, Ma CK, Blaser MJ, Perez-Perez GI, Schubert TT. Accuracy of invasive and noninvasive tests do diagnose Helicobacter pylori infection. Gastroenterology 1995; 109:109-36.

46. Breslin NP, O'Morain CA. Noninvasive diagnosis of Helicobacter pylori infection: a review. Helicobacter 1997; 2:111-7.

47. Brown KE, Peura DA. Diagnosis of Helicobacter pylori infection. Gastroenterol Clin North Am 1993; 22:105-15.

48. Gray SF, Wyatt JI, Rathbone BJ. Simplified techniques for identifying Campilobacter piloridis. J Clin Pathol 1986; 39:1279 (letter).

49. Chan WY, Hui PK, Chan JKC, Cheung PSY, Ng CS, Sham CH. Epithelial damage by Helicobacter pylori in gastric ulcers. Histopathology 1991: 19:47-53.

50. An International association between Helicobacter pylori infection and gastric cancer. The EUROGAST Study Group. Lancet 1993; 341:1359-62.

51. IARC Working Group on the evaluation of carcinogenic risks to human. Schistosomes, liver flukes and Helicobacter pylori. IARC Monogr Eval Carcinog Risks Hum 1994; 61:1-241.

52. Huang JQ, Sridhar $\mathrm{S}$, Chen $\mathrm{Y}$, Hunt $\mathrm{RH}$. Meta-analysis of the relationship between Helicobacter pylori seropositivity and gastric cancer. Gastroenterology 1998; 114:1169-79.

53. Uemura N, Okamoto S, Yamamoto S, Matsumura N, Yamaguchi S, Yamakido M, Taniyama K, Sasaki N, Schlemper RJ. Helicobacter pylori infection and the development of gastric cancer. N Engl J Med 2001; 345:784-9. 
54. Park HK, Sinar DR, Sloss RR, Whitley TW, Silverman JF. Histologic and endoscopic studies before and after gastric bypass surgery. Arch Pathol Lab Med 1986; 110:1164-1167.

55. Sundbom M, Hedenström H, Gustavsson S. Duodenogastric bile reflux after gastric bypass: a cholescintigrafic study. Dig Dis Sci 2002; 47:1891-1896.

56. Lynch DAF, Mapstone NP, Clarke AMT, Jackson P, Dixon MF, Quirke P, Axon ATR. Cell proliferation in the gastric corpus in Helicobacter pylori associated gastritis and after gastric resection. Gut 1995; 36:351-353.

57. Safatle-Ribeiro AV, Ribeiro U, Clarke MR, Sakai P, Ishioka S, Garrido Jr. AB, Gama-Rodrigues J, Safatle NF, Reynolds JC. Relationship between persistence of Helicobacter pylori and dysplasia, intestinal metaplasia, atrophy, inflammation and cell proliferation following partial gastrectomy. Dig Dis Sci 1999; 44:243-252.

58. Raijman I, Strother SV, Donegan WL.Gastric cancer after gastric bypass for obesity: Case report. J Clin Gastroenterol 1991;13:191-194.

59. Lord RV, Edwards PD, Coleman MJ. Gastric cancer in the bypassed segment after operation for morbid obesity. Aust N Z J Surg 1997; 67:580-582.

60. Khitin L, Roses RE, Birket DH. Cancer in the gastric remnant after gastric bypass: a case report. Curr Surg 2003; 60:521-523.

61. Escalona A, Guzman S, Ibanez L, Meneses L, Huete A, Solar A. Gastric cancer after Roux-en-Y gastric bypass. Obes Surg 2005; 15:423-7. 
62. Corsini DA, Simoneti CAM, Moreira G, Lima SE, Garrido AB. Cancer in the Excluded Stomach 4 Years after Gastric Bypass. Obes Surg 2006; 16: $932-934$.

63. Tytgat GN. The Sydney System: endoscopic division. Endoscopic appearances in gastritis/duodenitis. J Gastroenterol Hepatol 1991; 6:223-234.

64. Castro LP, Oliveira CA, Prolla JC, Magalhães AFN, Rezende JM. Sistema Sydney: uma nova classificação de gastrites. GED 1991; 10:75-82.

65. Price AB. The Sydney System: histological division. J Gastroenterol Hepatol 1991; 6:208-22.

66. I Consenso Brasileiro de doença do refluxo gastroesofágico; 2000; São Paulo.

67. Fobi MAL. Vertical banded gastroplasty vs. gastric bypass: 10 years follow-up. Obes Surg 1993; 3:161-164.

68. Capella JF, Capella RF. The weight reduction operation choice: vertical banded gastroplasty or gastric bypass. Am J Surg 1996; 171:74-79.

69. Wittgrove AC, Clark W. Laparoscopic gastric bypass, Roux-en-Y - 500 patients: technique and results with 3-60 month follow-up. Obes Surg 2000; 10:233-239.

70. Geltileschi P, Gagner M, Milone L, Kini, S, Fukuyama S. Histologic studies of the bypassed stomach after Roux-en-Y gastric bypass in a porcine model. Obes Surg 2006; 16:886-890. 
71. Alam K, Schubert TT, Bologna SD, Ma CK. Increased density of Helicobacter pylori on antral biopsy is associated with severity of acute and chronic inflammation and likelihood of duodenal ulceration. Am J Gastroenterol 1992; 87:424-428.

72. De Vries AC, Haringsma J, Kuipers EJ. The detection, surveillance and treatment of premalignant gastric lesions related to Helicobacter pylori infection. Helicobacter 2007; 12:1-15.

73. Fujimura J, Haruma K, Hata J, et al. Quantitation of duodenogastric reflux and antral motility by color Doppler ultrasonography. Study in healthy volunteers and patients with gastric ulcer. Scand J Gastroenterol $1994 ; 29: 897-902$

74. Fuchs $\mathrm{KH}$, Maroske $\mathrm{J}$, Fein $\mathrm{M}$, et al. Variability in the composition of physiologic duodenogastric reflux. J Gastrointes Surg 1999; 3:389-395.

75. Spechler SJ. The role of gastric carditis in metaplasia and neoplasia at the gastroesophageal junction. Gastroenterology 1999; 117:218-228.

76. Correa P. A human model of gastric carcinogenesis. Cancer Res 1988; 48:3554-60.

77. Voellinger DC, Inabnet WB. Laparoscopic Roux-en-Y gastric bypass with remnant gastrectomy for focal intestinal metaplasia of the antrum. Obes Surg 2002; 12:695-8.

78. Csendes A, Burdiles P, Papapietro K, Diaz JC, Maluenda F, Burgos A, Rojas J. Results of gastric bypass plus resection of the distal excluded gastric segment in patients with morbid obesity. $J$ Gastrointest Surg 2005; 9:121-131. 
79. Printen KJ, LeFavre J, Alden J. Bleeding from the bypassed stomach following gastric bypass. Surg Gynecol Obstet 1983; 156:65-66.

80. Macgregor AM, Pickens NE, Thoburn EK. Perforated peptic ulcer following gastric bypass for obesity. Am Surg 1999; 65:222-225.

81. Ross AS, Semrad C, Alverdy J, et al. Use of double-balloon enteroscopy to perform PEG in the excluded stomach after Roux-en-Y gastric bypass. Gastrointest Endosc 2006; 64:797-800.

82. Baron T. Double-balloon enteroscopy to facilitate retrograde PEG placement as access for therapeutic ERCP in patients with long-limb gastric bypass. Gastrointest Endosc 2006; 64:973-974.

83. Emmett DS, Mallat D. Endoscopic retrograde cholangiopancreatography using a double-balloon endoscope in Roux-en-Y surgical bypass patients: a case series. Gastrointest Endosc 2007; 65: AB236. 